\title{
Cross-border effects of fiscal policy in the Eurozone
}

Citation for published version (APA):

Bicu, A. C., \& Lieb, L. M. (2015). Cross-border effects of fiscal policy in the Eurozone. Maastricht University, Graduate School of Business and Economics. GSBE Research Memoranda No. 019 https://doi.org/10.26481/umagsb.2015019

Document status and date:

Published: 01/01/2015

DOI:

10.26481/umagsb.2015019

Document Version:

Publisher's PDF, also known as Version of record

\section{Please check the document version of this publication:}

- A submitted manuscript is the version of the article upon submission and before peer-review. There can be important differences between the submitted version and the official published version of record.

People interested in the research are advised to contact the author for the final version of the publication, or visit the DOI to the publisher's website.

- The final author version and the galley proof are versions of the publication after peer review.

- The final published version features the final layout of the paper including the volume, issue and page numbers.

Link to publication

\footnotetext{
General rights rights.

- You may freely distribute the URL identifying the publication in the public portal. please follow below link for the End User Agreement:

www.umlib.nl/taverne-license

Take down policy

If you believe that this document breaches copyright please contact us at:

repository@maastrichtuniversity.nl

providing details and we will investigate your claim.
}

Copyright and moral rights for the publications made accessible in the public portal are retained by the authors and/or other copyright owners and it is a condition of accessing publications that users recognise and abide by the legal requirements associated with these

- Users may download and print one copy of any publication from the public portal for the purpose of private study or research.

- You may not further distribute the material or use it for any profit-making activity or commercial gain

If the publication is distributed under the terms of Article $25 \mathrm{fa}$ of the Dutch Copyright Act, indicated by the "Taverne" license above, 


\section{Maastricht University}

Andreea Bicu, Lenard Lieb

Cross-border effects of fiscal policy in the Eurozone

RM/15/019

\section{GSBE}

Maastricht University School of Business and Economics

Graduate School of Business and Economics

P.O Box 616

NL-6200 MD Maastricht

The Netherlands 


\title{
Cross-border effects of fiscal policy in the Eurozone *
}

\author{
Andreea Bicu and Lenard Lieb ${ }^{\dagger}$
}

\begin{abstract}
We empirically assess spillovers from fiscal policy in the Euro area. We propose a structural multi-country factor-augmented vector autoregression model identified with sign restrictions and analyse the domestic and international effects of fiscal policy measures. By extracting information from an extended set of country specific and cross-border variables, we are able to account for the different channels through which government expenditure shocks are transmitted within as well as across borders. We find significant negative effects of fiscal consolidations on domestic output, private consumption and investment. More importantly, spending cuts in Italy and Spain induce significant and persistent output spillovers on Germany and France.
\end{abstract}

Keywords: Fiscal policy; Cross-border spillovers.

JEL Classification: E62; F42

\footnotetext{
${ }^{*}$ The authors thank Peter Pedroni for stimulating discussions and advice. We are also grateful for comments received at the 8th International Conference on Computational and Financial Econometrics in Pisa, at the Bank of England and during the Netherlands Econometric Study Group meeting in Maastricht.

${ }^{\dagger}$ Maastricht University, Department of Economics, Maastricht, The Netherlands.
} 


\section{Introduction}

The macroeconomic policy debate in the Euro area during the last five years has largely centred around the international dimension of fiscal policy. While there is a large empirical literature dealing with the effects of fiscal policy on the domestic economy, very few authors quantify the magnitude of cross-border spillovers (Auerbach and Gorodnichenko, 2013, Hebous and Zimmermann, 2013 inter alia). Such spillovers are particularly important in an economic, monetary and currency union such as the Eurozone. With strongly interconnected economies, policy measures implemented at the national level can have significant cross-border repercussions.

In order to assess the international dimension of fiscal policy measures, it may be necessary to extract information from a large number of domestic and foreign variables. Including a large number of countries and taking into account potential channels of transmission within as well as across borders results in an excessively complex, high dimensional dataset which becomes difficult to analyse with conventional econometric methods. Several modelling approaches have been considered in the literature: two-country models (Corsetti et al., 2010, Bénassy-Quéré and Cimadomo, 2007), Global Vector Autoregressions (Hebous and Zimmermann, 2013), aggregated foreign fiscal shocks (Auerbach and Gorodnichenko, 2013, Beetsma et al., 2006) or uni-directional effects in a panel regression setting (Hebous and Zimmermann, 2012). All of these papers rely on specific simplifications to bypass the "curse of dimensionality", either by limiting the number of cross-sectional units, restricting the channels of interdependence, imposing cross-sectional homogeneity, or disregarding dynamic feedback effects between units and variables.

We contribute to the literature of domestic and cross-border effects of fiscal policy in a number of ways. First, we motivate and introduce a multi-country Factor Augmented Vector Autoregression (MC-FAVAR) model where both observable and unobservable factors are included. To this aim, we combine the multi-country VAR approach of Canova and Ciccarelli (2009) with the FAVAR framework of Bernanke et al. (2005). Nested in an unrestricted VAR, our modelling approach is therefore better able to capture rich patterns of dynamic interdependence within as well as across borders. Second, we augment the set of country specific aggregates (output and its main components) with variables that seem to play an important role in the domestic transmission of fiscal policy shocks, for example real wages and a measure of business and consumer confidence. Third, we include cross-border variables relevant for capturing the strength of bilateral economic and financial links. As a result, we are able to extract important information captured by the channels through which fiscal spillovers materialise. Fourth, we pay particular attention to the identification of fiscal policy shocks in a multi-country setting. We opt for an agnostic, sign restriction approach similar to the one proposed by Mountford 
and Uhlig (2009) which is well suited for identifying country specific (domestic) government expenditure shocks.

We investigate the effects of (coordinated) fiscal policy shocks in a multi-country model comprising of the main core and peripheral Eurozone economies: Germany, France, Italy and Spain. We find that 1) domestic multipliers range between 0.5 for Italy and 1 for Germany and never surpass unity; 2) cross-border spillovers from contractionary fiscal policy are significant but, in contrast with the sizeable cross-border multipliers obtained by Hebous and Zimmermann (2013) and Auerbach and Gorodnichenko (2013), economic activity consistently reacts stronger to a domestic consolidation than to a foreign fiscal shock; 3) fiscal shocks originating in Italy and Spain have the strongest cross-border effects and spillovers are particularly large when these two peripheral countries jointly engage in a process of fiscal consolidation; 4) domestic confidence generally declines across all countries but we find mixed dynamics between confidence levels and sovereign bond yields, depending on whether the fiscal shocks originate in the peripheral economies (negative relationship) or core countries (positive relationship).

The goal of Section 2 is to shed more light on the complex issue of cross-border spillovers, both in terms of transmission channels as well as with regards to the modelling difficulties generally arising. In Section 3 , we discuss the data which we believe is relevant for addressing our research question and introduce the MC-FAVAR model used in the empirical analysis. In Section 4, we discuss in detail the identification of the underlying structural model and explain how we characterise coordinated fiscal policy shocks in a multi-country set-up. We summarise in Section 5 the domestic and cross-border effects of fiscal consolidation obtained using our multi-country model.

\section{Modelling cross-country fiscal spillovers}

\subsection{Channels of transmission}

With increasing integration, many authors have argued that the level of interdependence across countries has strengthened and that cross-border externalities are likely to represent a growing part of macroeconomic dynamics (Pesaran et al., 2007, Canova et al., 2007, Canova and Ciccarelli, 2012 inter alia). It is therefore crucial to account for interdependencies across countries and sectors when analysing the transmission of economic shocks in a system of interconnected economies. The strength of cross-border responses is strongly connected to these links: the stronger the countries are connected the larger spillovers are expected to be.

The primary channel of fiscal policy spillovers discussed in the literature is trade. Exist- 
ing theoretical models of open economies predict that an increase in government consumption will lead to higher import demand (twin deficit hypothesis) due to both direct effects (higher aggregate demand) and indirect effects (real exchange rate appreciation/price level increase). As a result of the deterioration in the trade balance, stimulus "leaks" reduce domestic fiscal multipliers but create a positive effect on foreign output. The transmission channel of the fiscal shock across borders is however heavily influenced by a series of factors such as the degree of openness of the economy, the "home bias" in government expenditures, the degree of substitution between foreign and home produced goods, the response of monetary policy, as well as the degree of price rigidity (see Corsetti et al., 2010, Corsetti and Müller, 2007, Beetsma, 2008, Nakamura and Steinsson, 2014).

Recent empirical papers dealing with the topic of fiscal spillovers also mainly focus on trade linkages. Auerbach and Gorodnichenko (2013) quantify empirically the dynamic cross-border effects of fiscal policy in OECD countries by using direct projections. In a first step, they identify domestic fiscal shocks as the unanticipated part of spending forecast errors after controlling for an extensive information set, and calculate trade weighted averages of foreign fiscal shocks for each country. The weighting scheme underlines the assumption that spillovers materialise through trade links: the increase in government purchases of country $i$ is partially directed into higher imports from country $j$. The authors find significant spillover effects from the aggregate foreign shocks and output multipliers exceeding one. A potential drawback is that their panel analysis uses aggregate fiscal innovations and is not suitable for tracing the cross-border effects of distinct, country specific shocks. Moreover, the homogeneity assumption underlying the panel specification implies that only average, group-specific spillover effects can be estimated. In a similar two-stage approach, Beetsma et al. (2006) first identify structural domestic fiscal shocks from a VAR model and, in a second step, evaluate whether it significantly influences the imports of country $i$ (domestic) from country $j$ (foreign). The authors find that a $1 \%$ increase in German government spending leads to an output response of about $0.1 \%$ in France, Italy and Spain after two years. ${ }^{1}$ It is, however, difficult to asses whether these responses are significantly different from zero since country-specific confidence intervals are not reported. Moreover, the final output spillovers are not computed from a system estimation but rather by combining (multiplying) responses from two independent steps. Hebous and Zimmermann (2012) use exogenous consolidation episodes based on narrative records and find that a foreign, trade weighted fiscal contraction induces a substantial decline in domestic output. The multipliers obtained are in the range of 3 to 7 for the first year following the shock. Similar to Auerbach and Gorodnichenko

\footnotetext{
${ }^{1}$ Maximum spillovers, of around $0.4 \%$ are found in Austria and Belgium.
} 
(2013), the effects are estimated by panel data regression techniques and thus important endogenous interactions among variables can no longer be analysed.

Another potentially important channel of policy spillovers may be generated through crossborder financial linkages. Krugman (2008) highlights the increasing importance of the "international finance multiplier" for the transmission of shocks in a globalised world economy and identifies financial institutions as the core source of interdependence between countries. There is a growing literature on the domestic and cross-border risk transmission between the sovereign and banking sectors in the Euro area (see e.g. Bicu and Candelon, 2013). The observed interconnectedness arises from important bail-out funds and guarantees used by governments, and, respectively, from massive purchases of sovereign debt by banks. Adjustments in governments' balance sheets resulting from both discretionary policy and changes in the risk perception of sovereign debt are hence expected to have an influence on bank's balance sheets and lending activity. The elimination of cross-border restrictions and harmonisation of regulation 2 led to a significant increase in the level of financial integration in the Eurozone. As a result, aggregate consumption and investment in one country can be affected by fluctuations in lending extended by foreign banks. More recently, following an increase in banking risk and a process of deleveraging, credit supply constraints have had a dampening impact on consumption and investment across the common currency area. Coupled with an economic environment characterised by low aggregate demand and high risk aversion, cross-border and domestic banking intermediation has experienced a gradual decline, further dampening economic growth across the common currency area 3 Recent experience has highlighted the pro-cyclical nature of capital flows and its destabilising role on economic activity within as well as across borders (Brunnermeier et al., 2012).

Empirical work on fiscal spillovers arising from financial linkages is more limited. Hebous and Zimmermann (2013) employ the Global VAR methodology in a sample of 12 Euro area countries and use weights calculated according to bilateral trade or capital flows when defining country specific foreign factors. The authors compare the output response following a domestic fiscal shock to that of an area-wide shock, i.e. a synchronised unit change in the primary budged deficit of all foreign countries. Across all Euro members, the spillovers from a coordinated, union-wide fiscal consolidation are stronger than the responses to a domestic shock. While this may not be considered an unreasonable result prima facie, the magnitude of spillovers relative

\footnotetext{
${ }^{2}$ For banking activity in the EU, the most notable first steps towards the single market were taken through the first and second banking directives (77/780/EEC and 89/646/EEC).

${ }^{3}$ Latest ECB data for 2014 show that loans extended by monetary and financial institutions to non-financial corporations and households within the Euro area are continuing to decline.
} 
to domestically induced fiscal effects is unrealistically large. Furthermore, the use of generalised impulse responses (Pesaran and Shin, 1998) makes a structural interpretation of the identified fiscal policy shocks difficult.

Moving beyond classical balance sheet connections ("real" channels), Bachmann and Sims (2012) show that psychological factors may matter for the propagation of fiscal policy shocks. The authors find that output and confidence levels react positively to fiscal expansions. When blocking the confidence channel, the output reaction is much weaker, especially in times of crisis. Taking into account the central role of economic sentiment in the European austerity debate, it is relevant to understand how domestic and foreign confidence indicators react when each of the countries included in our empirical analysis engages in a process of fiscal consolidation. Confidence indicators capture systematic developments in business and consumer expectations and contain signals from other relevant but unmodelled variables. Hence, psychological factors are likely to to play a role in the transmission of fiscal shocks in a monetary union 4 To our knowledge, there is no empirical paper which investigates the link between confidence and fiscal policy spillovers.

\subsection{Multi-country modelling approaches}

Modelling multi-country dynamics in a coherent econometric framework is difficult. On the one hand, failing to include a large set of variables, to control for all relevant channels through which spillovers may arise can lead to omitted variables bias. On the other hand, including a large number of countries and variables, which may be relevant for disentangling the effects of policy from other shocks, makes estimating an unrestricted model unfeasible: the number of parameters to estimate increases exponentially with the cross-sectional size, while the number of observations only increases linearly. The parameter proliferation issue results in noisy estimates, unstable predictions and difficult to interpret temporal dependence. To tackle this issue of reducing dimensionality in a dynamic framework, several approaches have been suggested in the literature. Typically these are nested in an unrestricted VAR model. Frequently used models include the Global VAR (GVAR), collections of bilateral VARs, Bayesian VARs, sparse VARs, Panel VARs, or factor models.

The GVAR (Pesaran et al., 2004, Dees et al., 2007) was developed for the purpose of capturing spillovers in multi-country analyses, where a particular structure on the strength of interdependencies is imposed. Each country-specific VAR is augmented with a foreign factor, calculated

\footnotetext{
${ }^{4}$ High risk aversion and "flight-to-quality" reactions have played an important role in the pricing of sovereign debt during the crisis (see, inter alia, De Grauwe and Ji, 2012). The systematic link between fiscal consolidations, confidence and sovereign bond yields may be relevant to investigate as well.
} 
as a weighted average of foreign variables according to economic or financial bilateral links. The GVAR is a large constrained VAR, where restrictions arise as a result of the weights imposed on foreign variables, as well as from the exogeneity of each foreign factor with respect to the long run parameters of the corresponding domestic VAR. Since the GVAR is designed to be used in applications with a large cross-sectional dimension, these exogeneity assumptions can be interpreted as no long-run feedback from any individual country (except the dominant unit) to the dynamics of the foreign factor. While the GVAR has some appealing features, a series of concerns have been raised regarding the factorisation of the joint density for the domestic and foreign variables (see Ericsson, 2011). Furthermore, imposing weak exogeneity restrictions and estimating each country-specific VAR independently may not be justified for our empirical analysis, given that we include a small number of countries that are strongly interconnected. The implications of the underlying restrictions for the dynamics of the system and for the transmission of shocks across countries are difficult to assess. Considering these drawbacks, we do not purse this direction further.

Bayesian VARs represent another approach for overcoming the curse of dimensionality. Macroeconomic time series tend to exhibit a high degree of comovement. As argued by De Mol et al. (2008), when significant collinearity is present in the data, the relevant factors driving most of the dynamics in the data can be extracted through Bayesian shrinkage techniques. When analysing the effects of a monetary policy shock in a large scale VAR, Banbura et al. (2010) use the Minnesota prior to shrink the diagonal elements of the VAR parameter matrix to zero or one, depending on the order of integration, and the remaining coefficients to zero. The authors find that their shrinkage procedure leads to credible impulse responses. The main drawback of such a shrinkage procedure when applied in a multi-country setting is that it indiscriminately shrinks all non-diagonal coefficients to zero, disregarding the panel structure of the data. This also restricts the transmission of shocks across countries, since coefficients capturing cross-border interdependencies are effectively reduced towards zero.

Sparse estimation methods in a VAR setting, such as the Lasso (e.g. Kock and Callot, 2015), suffer from similar shortcomings. The Lasso estimator applies an equal penalisation and, hence, the same amount of shrinkage for each parameter. Considering the strong comovement in domestic macroeconomic aggregates and significant cross-border interdependence, zero restrictions and sparsity patterns are difficult to reconcile with economic intuition.

A more suitable approach to limit parameter proliferation in macroeconomic analyses is the multi-country VAR framework of Canova and Ciccarelli (2009). Canova and Ciccarelli model the cross-sectional dependence in terms of an observable factor model and use unweighted lin- 
ear combinations of right-hand-side variables as regressors. The estimation problem is reduced to identifying a small number of loadings, and the coefficients are decomposed into effects induced by variable, country, equation specific factors and other common indicators which may be deemed relevant for the empirical question analysed. While providing an intuitive and interpretable way of capturing commonalities in the data, this economically motivated but relatively ad-hoc modelling approach may not result in the best statistical fit. It is likely that the leftover unexplained component still contains unmodelled commonality and serial correlation not picked up by these observable factors. Moreover, important driving forces and channels for the transmission of shocks across borders (in particular bilateral trade and financial relationships), cannot be easily incorporated in this factor structure. To account for any unmodelled features of the data (and thus to provide a better fit to the data), Canova and Ciccarelli allow for time varying parameters. In our view, this would complicate a structural analysis since the parameter drifting is introduced ad-hoc (and not based on economic arguments) and, hence, lacks a genuine structural interpretation: $[5$

Dynamic factor models (Forni et al., 2000, 2005) and factor augmented VAR (FAVAR) models (Bernanke et al., 2005) rely on the assumption that a significant proportion of the movements and interdependence in a set of time series can be captured through a small number of common factors. The factors are extracted through statistical techniques and are, hence, unobservable and difficult to interpret ${ }^{6}$ We believe that it is crucial to identify an interpretable structure based on economic intuition in parallel with adding statistical factors to account for any remaining commonalities. Moreover, the dynamic responses of a large set of (country-specific) variables are of interest for the identification of structural fiscal policy shocks (see Section 4), making the estimation of an unrestricted FAVAR unfeasible.

To tackle some of the major challenges posed by the listed empirical approaches, we propose a dynamic model consisting of observed and unobserved factors which is nested in a VAR. More specifically, we combine the multi country VAR approach of Canova and Ciccarelli (2009) with the FAVAR framework of Bernanke et al. (2005) and summarise the information captured by our variables through a reduced number of observable and unobservable factors. In Section 3.2 we will describe in more detail the exact specification used.

\footnotetext{
${ }^{5}$ Furthermore, the estimation of time-varying parameter VARs is usually carried out in a Bayesian framework, and it is much less straightforward to implement when relying on a frequentist approach, which we will consider in this paper.

${ }^{6}$ Suitably selected rotations may partially alleviate this issue and allow the factors to be directly associated to a specific variable or sets of variables.
} 


\section{Empirical analysis}

\subsection{Data}

We include in our empirical analysis the four largest economies in the common currency area: Germany, France, Italy, and Spain. $]^{7}$ All variables are of quarterly frequency and the time period covered is 1999:Q1 to 2012:Q4 8

The main variables of interest for our analysis correspond to domestic macroeconomic aggregates, namely output (GDP) and its main components, private consumption and investment. As a measure of fiscal policy, we are consistent in our variable definition with Blanchard and Perotti (2002) and Mountford and Uhlig (2009) and calculate government expenditures by aggregating government final consumption expenditure and investment. We augment the set of domestic variables with data on real wages, unit labour costs (ULC), and the harmonised consumer price index (HCPI). Theoretical closed economy models predict that the output effect of fiscal policy is crucially influenced by the reaction of real wages. While models based on Neoclassical theory predict a decline in real wages and, as a result, a drop in private consumption, New-Keynesian models imply a positive reaction in wages and consistently find larger output multipliers. Moreover, measures of relative competitiveness such as unit labor costs and the general price level may be relevant for disentangling the effects of policy changes, both domestically and across borders. Referring to the confidence channel previously highlighted, we include Eurostat's Economic Sentiment Indicator (ESI) as well as 10-year sovereign bond yields. The ESI summarises survey responses across five sectors (industry, services, construction, retail trade and consumers) and represents an aggregate measure of consumer and business confidence. Long-term borrowing costs are a direct indicator of how a government's creditworthiness is perceived by the market and reflect both fundamental as well as risk aversion/confidence factors. This set of nine time series are relevant for the transmission of fiscal policy changes within country borders and have a clear panel structure. We refer to these series as domestic variables.

We believe that further extracting information from bilateral variables capturing the strength of economic and financial links is crucial for our empirical analysis. To this aim, we include bilateral exports for each pair of countries in our sample and, as a measure of bilateral financial links, cross-border claims of internationally active banks. The financial system in Europe is mainly bank based, with the banking sector providing around $70 \%$ of funding. As a result, the majority of capital flows are channeled across borders through global banks (Brunnermeier et al., 2012). We use data on "Consolidated claims, immediate borrower basis"

\footnotetext{
${ }^{7}$ These countries cover about $77 \%$ of total output (GDP) in the Eurozone.

${ }^{8}$ For a more detailed description of the data and sources used, see Appendix A.
} 
collected by the Bank of International Settlements (BIS), which have been widely used for monitoring the cross-border exposures of internationally active banks. These consolidated statistics are reported at country level and aggregate the international claims of all banks headquartered in the respective country. This covers quarterly balance sheet positions of reporting banks, including loans, deposits, securities and derivative contracts. The cross-border bank claims have as counterparty a foreign debtor in either the bank, non-bank, private or public sector.

We transform all variables, except the confidence measure and price/costs series, in real per capita terms and calculate year-on-year growth rates. Furthermore, we standardise each growth rate in order to account for different variability patterns across variables. The need for standardisation, which will become apparent in Section 3.2 , is motivated by the fact that the regressors in our model are constructed as unweighted averages across different data dimensions ${ }^{9}$

\subsection{The multi-country factor augmented vector autoregressive model (MC- FAVAR)}

Our model builds on the multi-country VAR framework of Canova and Ciccarelli (2009). Canova and Ciccarelli model the cross-sectional dependence in terms of an observable factor model and allow for dynamic interdependencies between units (countries). We start motivating our model with an unrestricted $\operatorname{VAR}(1)$ which stacks the domestic variables $y_{i, t}$ :

$$
\left[\begin{array}{c}
y_{1, t} \\
y_{2, t} \\
\cdots \\
y_{N, t}
\end{array}\right]=\left[\begin{array}{c}
\Gamma_{1} \\
\Gamma_{2} \\
\cdots \\
\Gamma_{N}
\end{array}\right]\left[\begin{array}{c}
y_{1, t-1} \\
y_{2, t-1} \\
\ldots \\
y_{N, t-1}
\end{array}\right]+\left[\begin{array}{c}
e_{1, t} \\
e_{2, t} \\
\cdots \\
e_{N, t}
\end{array}\right],
$$

where $y_{i, t}$ is a $K \times 1$ vector of variables for each country $i, i=1, \ldots, N, t=1, \ldots, T, \Gamma_{i}$ is of size $K \times K N$ and $e_{i, t}$ is a $K \times 1$ vector of disturbances. With a limited number of times series observations and a large number of parameters $\left(K^{2} N^{2}\right)$, we are unable to estimate all coefficients without imposing restrictions. We need to reduce the dimensionality of the model while minimising the loss of information arising from the restrictions imposed. Following Canova and Ciccareli (2009), we first rewrite the VAR in SUR form:

$$
Y_{t}=W_{t} \gamma+e_{t}
$$

\footnotetext{
${ }^{9}$ Since we still found evidence of a trending behaviour, we further linearly de-trended six of our 60 time series prior to the standardisation.
} 
with $Y_{t}=\left[y_{1, t}{ }^{\prime}, y_{2, t^{\prime}}, \ldots, y_{N, t^{\prime}}\right]^{\prime}, W_{t}=I_{N K} \otimes Y_{t-1}^{\prime}$, and $\gamma=\left(\gamma_{1}^{\prime}, \ldots, \gamma_{N}^{\prime}\right)^{\prime}$, where $\gamma_{i}$ are $N K \times 1$ vectors containing the $K$ stacked rows in $\Gamma_{i}, i=1, \ldots, N$. Since an unrestricted estimation of $\gamma$ is not possible, Canova and Ciccareli (2009) propose decomposing the parameters into a lower dimensional set of determinants:

$$
\gamma=\Omega \theta+u=\Omega_{1} \theta_{1}+\Omega_{2} \theta_{2}+\ldots+\Omega_{f} \theta_{f}+u,
$$

where the components of $\theta$ (i.e. $\theta_{i}, i=1, \ldots, f$ ) account for effects due to either country specific, variable specific or other "factors" which may be relevant for each specific empirical question and data structure. $\Omega=\Omega_{1}, \ldots, \Omega_{f}$ are selection matrices that aggregate the information in the lagged series according to specific data dimensions. Finally, $u$ represents the left-over, unexplained component. Substituting the parameterisation (3) into the VAR model (2), we obtain:

$$
Y_{t}=\sum_{i=1}^{f} W_{t}\left(\Omega_{i} \theta_{i}+u\right)+e_{t}=\sum_{i=1}^{f} F_{i t} \theta_{i}+\epsilon_{t}
$$

where $F_{i t}=W_{t} \Omega_{i}$ and $\epsilon_{t}$ contains remaining unmodelled features not captured by the factorisation as well as random disturbances. It is easy to see from representation (4) that the VAR is now rewritten as an observable factor model. The explanatory factors are linear combinations of appropriately selected right-hand-side variables. In contrast to a typical VAR, where the effect on each left-hand-side variable is allowed to be different, the coefficients are now composed of qualitatively equal responses across certain data categories and dimensions.

Similar to Canova and Ciccarelli (2009), we decompose the VAR parameters into $K$ variable specific and $K N$ equation specific determinants. The exact interpretation of these effects ("loadings") will be clarified through the example described below. As an additional distinct feature of our model, we allow the aggregate information in each country to induce a different effect, depending on whether the modelled relationships are captured within-country or are due to foreign influences. To this aim, we differentiate between "Home" $\left(\mathcal{H}=\left\{\mathcal{H}_{1}, \mathcal{H}_{2}, \ldots, \mathcal{H}_{N}\right\}\right)$ and "Cross-border" influences $\left(\mathcal{C}=\left\{\mathcal{C}_{j \rightarrow i}, i \neq j\right\}\right)$, where the latter quantify the effect of country $j$ on $i$. Notice that we therefore allow for different strengths of spillovers among all pairs of countries. In total, we decompose the $K^{2} N^{2}$ parameters in $K+K N+N+N(N-1)$ distinct "loadings", corresponding to the effects induced by each variable, equation and country factors respectively.

Let us illustrate our VAR(1) re-parameterisation through a simplified two countries $(N=2)$, two variables $(K=2)$ example. The $K \times K N$ elements of $\Gamma_{i}, i \in\{1,2\}$ represent the impact that the lagged regressors, both domestic and foreign, exert on each of the $K$ domestic variables in 
country $i$. By using the set of factors described above, the coefficients are now decomposed into economically interpretable effects: i.e. equation specific $\mathcal{E}=\left\{\mathcal{E}_{1}, \mathcal{E}_{2}, \mathcal{E}_{3}, \mathcal{E}_{4}\right\}$, variable specific, $\mathcal{V}=\left\{\mathcal{V}_{1}, \mathcal{V}_{2}\right\}$, home specific $\mathcal{H}=\left\{\mathcal{H}_{1}, \mathcal{H}_{2}\right\}$ and cross-border specific $\mathcal{C}=\left\{\mathcal{C}_{1}, \mathcal{C}_{2}\right\}$

$$
\left[\begin{array}{l}
\Gamma_{1} \\
\Gamma_{2}
\end{array}\right]=\left[\begin{array}{llll}
\mathcal{E}_{1}+\mathcal{V}_{1}+\mathcal{H}_{1} & \mathcal{E}_{1}+\mathcal{V}_{2}+\mathcal{H}_{1} & \mathcal{E}_{1}+\mathcal{V}_{1}+\mathcal{C}_{1} & \mathcal{E}_{1}+\mathcal{V}_{2}+\mathcal{C}_{1} \\
\mathcal{E}_{2}+\mathcal{V}_{1}+\mathcal{H}_{1} & \mathcal{E}_{2}+\mathcal{V}_{2}+\mathcal{H}_{1} & \mathcal{E}_{2}+\mathcal{V}_{1}+\mathcal{C}_{1} & \mathcal{E}_{2}+\mathcal{V}_{2}+\mathcal{C}_{1} \\
\mathcal{E}_{3}+\mathcal{V}_{1}+\mathcal{C}_{2} & \mathcal{E}_{3}+\mathcal{V}_{2}+\mathcal{C}_{2} & \mathcal{E}_{3}+\mathcal{V}_{1}+\mathcal{H}_{2} & \mathcal{E}_{3}+V_{2}+\mathcal{H}_{2} \\
\mathcal{E}_{4}+\mathcal{V}_{1}+\mathcal{C}_{2} & \mathcal{E}_{4}+\mathcal{V}_{2}+\mathcal{C}_{2} & \mathcal{E}_{4}+\mathcal{V}_{1}+\mathcal{H}_{2} & \mathcal{E}_{4}+\mathcal{V}_{2}+\mathcal{H}_{2}
\end{array}\right]
$$

Each distinct component of the factorised parameter matrix (5) can be obtained by regressions on appropriately selected combinations of the lagged domestic series. More specifically, we aggregate the right hand side information contained in each equation $\left(\chi_{t}^{E}=\sum_{i=1}^{N} \sum_{j=1}^{K} y_{i, j, t-1}\right)$, each domestic variable $\left(\chi_{t}^{\text {variable } 1}=\sum_{i=1}^{N} y_{i, 1, t-1}\right.$ and $\left.\chi_{t}^{\text {variable } 2}=\sum_{i=1}^{N} y_{i, 2, t-1}\right)$ and each country $\left(\chi_{t}^{\text {country } 1}=\sum_{j=1}^{K} y_{1, j, t-1}\right.$ and $\left.\chi_{t}^{\text {country } 2}=\sum_{j=1}^{K} y_{2, j, t-1}\right)$. Underlining such decomposition is the empirical observation of significant comovement present within each country and for the same variable measured across countries. Each component of the parameter matrix can therefore be interpreted as the loading on an observable factor, i.e. the respective sum of covariates $\sqrt{10}$ The equation specific component, for example, will capture an effect which is common for each row of the VAR. Alternatively, since the same lagged explanatory variables are included in all VAR equations, these effects can be interpreted as $K N$ distinct responses of each left hand side variable to a common indicator $\left(\chi_{t}^{E}\right) \cdot \chi_{t}^{\text {country } 1}$ and $\chi_{t}^{\text {country } 2}$ capture the dynamics of all domestic variables in countries one and two. This information will be used to trace the components in the parameters attributed to home and foreign effects, depending on the panel individual whose dynamic movements we are trying to explain. With two countries, the foreign factor for the first country is fully captured by the country specific variables of country two and vice-versa. The number of parameters to be estimated has declined from $16\left(K^{2} N^{2}\right)$ to 10 (four equation specific loadings, two variable loadings, two home and two foreign effects). It is easy to see that the improvement in terms of dimensionality reduction is much more pronounced when the number of countries and variables increases.

If the parameterisation of the VAR in (5) is able to fully capture the serial and cross-sectional correlation in our domestic time series, this model is well suited to conduct a multi-country analysis within a VAR framework. However, our tight parameterisation might not capture all serial dependence in the data. Furthermore, by not including relevant bilateral variables, we might

\footnotetext{
${ }^{10}$ Standardising all growth rates in a first step, as discussed in Section 3.1. ensures that the equal weighting scheme is suitable.
} 
omit information which is important for the transmission and recovery of structural shocks. We therefore augment our multi-country VAR with bilateral variables capturing trade and financial links $\left(X_{t}\right)$. These time series capture valuable insights into the transmission channels through which fiscal policy shocks spill over across borders. These variables do not have an obvious panel structure and it is unclear where to position them in the multi-country VAR. Are exports from Germany to Spain a German specific or a Spain specific variable? Similarly in the case of cross-border claims, would an increase in the willingness of German banks to lend to Italian counterparties signal a positive outlook for Germany (supply) or rather for Spain (demand)?

As a solution to this modelling uncertainty, as well as to account for any remaining systematic component in the country specific variables that our factorisation was not able to capture, we further augment our multi-country VAR with latent factors. Our main interest lies in quantifying the effect of fiscal measures on economic activity, within as well as across borders. The countryspecific/panel variables and their dynamics are at the core of the shock identification procedure and are relevant for disentangling the effects of fiscal policy from other shocks, as we will describe in Section 4. However, additional data might still be relevant when quantifying the effect of fiscal policy in a multi-country model. We assume that the fluctuations in the bilateral (crossborder) variables $X_{t}$ and the leftover unexplained component in the domestic variables $Y_{t}$ can be captured by a reduced number of latent factors $F_{t}$. We augment the multi-country VAR with these factors and our final model is a FAVAR with both observable and unobservable factors.

The joint dynamics of the domestic variables $Y_{t}$ and the $r$ latent factors $F_{t}$ are described by the following FAVAR model:

$$
\left[\begin{array}{l}
Y_{t} \\
F_{t}
\end{array}\right]=\left[\begin{array}{ll}
A & B \\
C & D
\end{array}\right]\left[\begin{array}{l}
Y_{t-1} \\
F_{t-1}
\end{array}\right]+w_{t},
$$

The relatively short time series dimension makes an unconstrained estimation of (6) unfeasible and we impose a number of restrictions on the parameter matrices in the FAVAR (6). The upper left block of the parameter matrix, $A$, is a $K N \times K N$ matrix capturing within country and cross-country interdependence among our macroeconomic variables of interest. The elements of $A$ will be decomposed according to the factorisation described by (5), i.e. equation, variable, home and foreign influences. The $r \times K N$ matrix $C$ traces the influence of country specific aggregates on the latent factors. We also factorise these effects in line with the structure imposed for $A$, with the difference that differentiating between home and foreign effects is no longer possible due to the latent nature of $F_{t}$. It is important to highlight that while the factorisation and the 
underlying linear combinations used to obtain the factorisation is almost identical for $A$ and $C$, the actual loadings are, however, allowed to be different. $B$ is of size $K N \times r$ and traces the effects of the unobserved factors on our aggregate macroeconomic fundamentals while the $r \times r$ matrix $D$ describes the time dependence of the latent factors. We leave $D$ and $B$ unconstrained, since it is not clear what type of factorisation could be applied with respect to the unobserved factors $F_{t}$. We therefore impose no a priori restrictions on the effect of the country variables $Y_{t}$ on $F_{t}$ nor on the autoregressive structure of the latent factors.

It is not possible, however, to directly estimate (6) because the factors are unobservable. The common factors are related to the set of $M$ bilateral (informational) variables $X_{t}$ and the remaining unexplained dynamics after the factorisation is applied to the domestic variables $Y_{t}$, as described by the following auxiliary model:

$$
\left[\begin{array}{l}
Y_{t} \\
X_{t}
\end{array}\right]=\left[\begin{array}{ll}
\Phi & 0 \\
0 & 0
\end{array}\right]\left[\begin{array}{c}
Y_{t-1} \\
X_{t-1}
\end{array}\right]+\boldsymbol{\Lambda}^{\boldsymbol{F}} \boldsymbol{F}_{\boldsymbol{t}}+v_{t}
$$

where $\Lambda^{F}$ is a $(K N+M) \times r$ parameter matrix. We use the auxiliary model $(7)$ to extract the latent factors $F_{t}$. $\Phi$ captures the within-country and cross-border dependencies for our variables of interest in $Y_{t}$ and has, again, the same factorised structure as the parameter matrix $A$ described above. The remaining parameters in the auxiliary model are set to zero since it is not clear what type of factors associated with the cross-border variables could be defined. The cross-sectional common information and time dependence in $Y_{t}$ not captured by $\Phi Y_{t-1}$, as well as the cross border variables $X_{t}$ will therefore be parsimoniously described by a reduced number of unobservable factors $F_{t}$. By imposing an interpretable structure on $\Phi$, we are able to label and clearly interpret the type of information contained in our observable factors and even quantify the relative importance of each factor in explaining the dynamics of our variables of interest $Y_{t}$. Any systematic components in the cross-border variables and the remaining unmodelled features in $Y_{t}$ are extracted through a principal component analysis.

After obtaining an estimate for $F_{t}$, the multi-country FAVAR (6) can be estimated by GLS (see Appendix B for an outline of the estimation strategy for the auxiliary and the multi-country FAVAR model. We identify two latent factors.). Using the $R^{2}$ as a "goodness-of-fit" measure, we find that our final model (6) is able to explain a significant percentage of the dynamic movements and variation in the $N K$ domestic variables contained in $Y_{t}$. We obtain an $R^{2}$ of $43 \%$ when only the factorisation (5) is applied and $72 \%$ when we further include latent factors. 


\section{Identification}

Based on our final model, the multi-country FAVAR (6), we now proceed by describing the identification approach. Identification in the VAR literature aims at translating the one-periodahead forecast errors, $w_{t}$, into economically interpretable (fundamental or structural) shocks, say $\eta_{t}$. The $K N+r$ structural shocks, which are mutually orthogonal and assumed to have unit variance, are defined as $P \eta_{t}=w_{t}$, where $P$ has the property $P P^{\prime}=\Sigma_{w}$. Each column $p_{j}, j=1, . ., K N+r$, of $P$ corresponds to an impulse vector of a one standard error innovation in the respective fundamental shock $\eta_{j t}$, the $j$-th entry of $\eta_{t}$. Since the exact identification of one impulse vector corresponds to the exact identification of one shock, only $m$ columns of $P$ have to be identified if one is interested in a subset of $m<K N+r$ shocks. There is a variety of possible decompositions of $\Sigma_{w}$ that orthogonalise the impulse responses (Cholesky, spectral, Schur, etc.). Note, however, that any such orthogonalised impulse matrix $P$ can be rotated by an orthogonal matrix $Q=\left[q_{1}, \ldots, q_{K N+r}\right]$ such that $\tilde{P}=P Q, \tilde{P} \tilde{P}^{\prime}=\Sigma_{w}$. Each rotation results in a different decomposition and in different impulse vectors $\left[\tilde{p}_{1}, \ldots, \tilde{p}_{K N+r}\right]=\left[P q_{1}, \ldots, P q_{K N+r}\right]$.

We identify structural shocks by using sign restrictions. The idea of identifying a structural shock through sign restrictions is as follows: given a matrix $P$, collect all unit vectors $q$ such that the impulse responses associated to the impulse vector $\tilde{p}=P q$ fulfil the imposed sign restrictions, discard the others. The object of interest is thus the set of valid impulse responses. This corresponds to the pure sign restriction approach proposed by Uhlig (2005). The identification of multiple impulse vectors (i.e. multiple shocks), say $\tilde{p}_{1}=P q_{1}$ and $\tilde{p}_{2}=P q_{2}$, obviously requires the additional restriction $q_{1}^{\prime} q_{2}=0$. In contrast, the penalty function approach of Mountford and Uhlig (2009) exactly identifies an impulse vector ${ }^{11}$ by minimising some criterion function which penalises corresponding impulse responses in the wrong direction and rewards responses in the desired directions. The exact identification of impulse responses greatly simplifies the construction of inference, in particular within a frequentist framework 12 In our setting, the penalty function approach appears to be particularly appealing for identifying domestic shocks. Since the responses in certain domestic variables are pushed as far as possible in the desired direction, we can interpret the sign identified structural shocks as being country specific (idiosyncratic) and limit the probability that such movements may be due to other common or foreign influences.

For each country we identify a government spending shock and a business cycle shock (8 shocks in total) that are, by construction, mutually orthogonal. In particular, the orthogonality

\footnotetext{
${ }^{11}$ and, hence, a unique structural model

${ }^{12}$ See Moon et al. (2013).
} 
between the fiscal and business cycle shocks rules out the impact of automatic stabilisers on fiscal variables and help us distinguish genuine fiscal policy shocks from movements due to business cycle influences. If we would not control for the stance of the economy, we could easily end up confusing a decrease in government expenditures caused by an economic upswing with a decline in government spending due to a contractionary policy. Let us now describe in detail the sign restrictions employed in the identification procedure. We identify country specific business cycle shocks $:^{13}$ as impulse vectors of unit length that jointly move domestic output, consumption and investment in the same direction for the first four quarters following the shock, including the quarter of impact. Such comovements can result from a number of different supply and demand shocks. In line with Mountford and Uhlig (2009), we do not try to separate such causes and remain agnostic with respect to how business cycles may arise. The "basic" (non-coordinated) fiscal policy shocks are identified as impulse vectors that jointly move domestic government spending in the same direction during four consecutive quarters. All fiscal shocks are orthogonal to each other and to the business cycle shocks. Note that our fiscal shocks do not restrict the dynamics of GDP and its components: the resulting dynamics of domestic and foreign output in response to our fiscal shocks represent our main quantity of interest.

These four country specific fiscal shocks offer valuable insights into the domestic and crossborder effects of fiscal policy. However, since no restrictions are imposed on the dynamics of government expenditures in the remaining economies, it may be difficult to disentangle pure, domestically induced output responses from influences due to comovements in other policy variables. Moreover, current fiscal developments in the Euro area can rather be seen as joint implementation of policy interventions across countries. As such, it may be more relevant to trace the effects of combinations of these basic shocks and define different policy scenarios of interest. Such policy interventions are defined through linear combinations of basic spending shocks that generate a desired combined response in domestic and foreign expenditures. We interpret these linear combinations as coordinated policy scenarios and view the resulting output responses as the effects of coordinated fiscal policy shocks. In particular, we analyse three different linear combinations of basic, structural shocks defined by the following joint dynamics/restrictions:

- Scenario 1: Government spending in Spain, Italy, France or Germany decreases by one

\footnotetext{
${ }^{13}$ One could also imagine a common shock originating outside the Euro area (e.g.: US policy change, oil supply shock, economic crisis in the ROW). However, such shocks can hardly be considered to be fundamental with respect to the variables included in the model. This implies that the space spanned by the reduced form errors (and thus by the information in the observed data included in the model) would not correspond to the space of such "structural" shocks. This makes a recovery of such structural shocks from the estimated reduced form errors impossible.
} 
percent for four quarters while expenditures in the remaining three countries remain unchanged.

- Scenario 2: Government spending in Spain and Italy (South) decreases by one percent for four quarters while expenditures in France and Germany (North) remain unchanged.

- Scenario 3: Government spending in Spain and Italy (South) decreases by one percent for four quarters while expenditures in France and Germany (North) increase by one percent.

\section{Results}

\section{1 "Plain-vanilla" VAR}

Before we present the results using our multi-country FAVAR, it is relevant to understand how a more simple model would perform in identifying the domestic and cross-border effects of fiscal policy. Is including only a very small number of variables in a VAR sufficient to reasonably identify the effects of fiscal policy? Would disregarding bilateral trade and financial linkages still result in meaningful, interpretable spillover effects?

To this aim, we first estimate a four-country unrestricted $\operatorname{VAR}(1)$ where only output and government expenditures are included. The four fiscal shocks are identified by sign restrictions, and are linearly combined to replicate Scenario 1 above. Each of the four graphs in Figure 1 . titled Germany, France Italy, Spain, include the response of that particular GDP to each of the four (coordinated) domestic fiscal shocks (Scenario 1). These graphs, therefore, summarise both domestic effects (the response in country $i$ to a shock $i, i=1, \ldots, 4$ ) as well as spillovers (response of GDP in country $i$ to a shock $j, j \neq i$ ). Filled markers indicate significant responses at the $68 \%$ level. While we, of course, do not know how domestic and foreign economic aggregates actually respond to fiscal shocks, we are still able to interpret whether the responses obtained look reasonable. First, we notice that economic activity in Germany and Italy reacts stronger and more persistently to a foreign (French) consolidation than to a domestic fiscal shock. The magnitude of the response in German GDP is, at times, even larger when compared to the output effect in the country where the shock originates. While we believe that the Eurozone countries share strong ties and that domestic shocks have significant cross-border effects, we find it difficult to reconcile these findings with economic intuition. Such results resonate with the unreasonably large spillovers obtained by Hebous and Zimermann (2013). Second, we obtain

\footnotetext{
${ }^{14}$ omitting the orthogonality restriction on a business cycle shock, which we are no longer able to identify in a meaningful way from one variable (GDP)
} 
both positive and negative output responses to a fiscal consolidation in Germany. What is, however, counterintuitive is that these delayed, positive spillovers on France and Italy and Spain arise after the negative domestic influence of the German shock has already died out. Third, Italian and Spanish shocks do not appear to induce significant effects on any of the two core countries. This result is particularly puzzling for the Spanish shock, considering the negative, significant and long lasting output impact of a domestic fiscal consolidation in Spain.

\section{Output responses to coordinated contractionary domestic fiscal shocks
France}
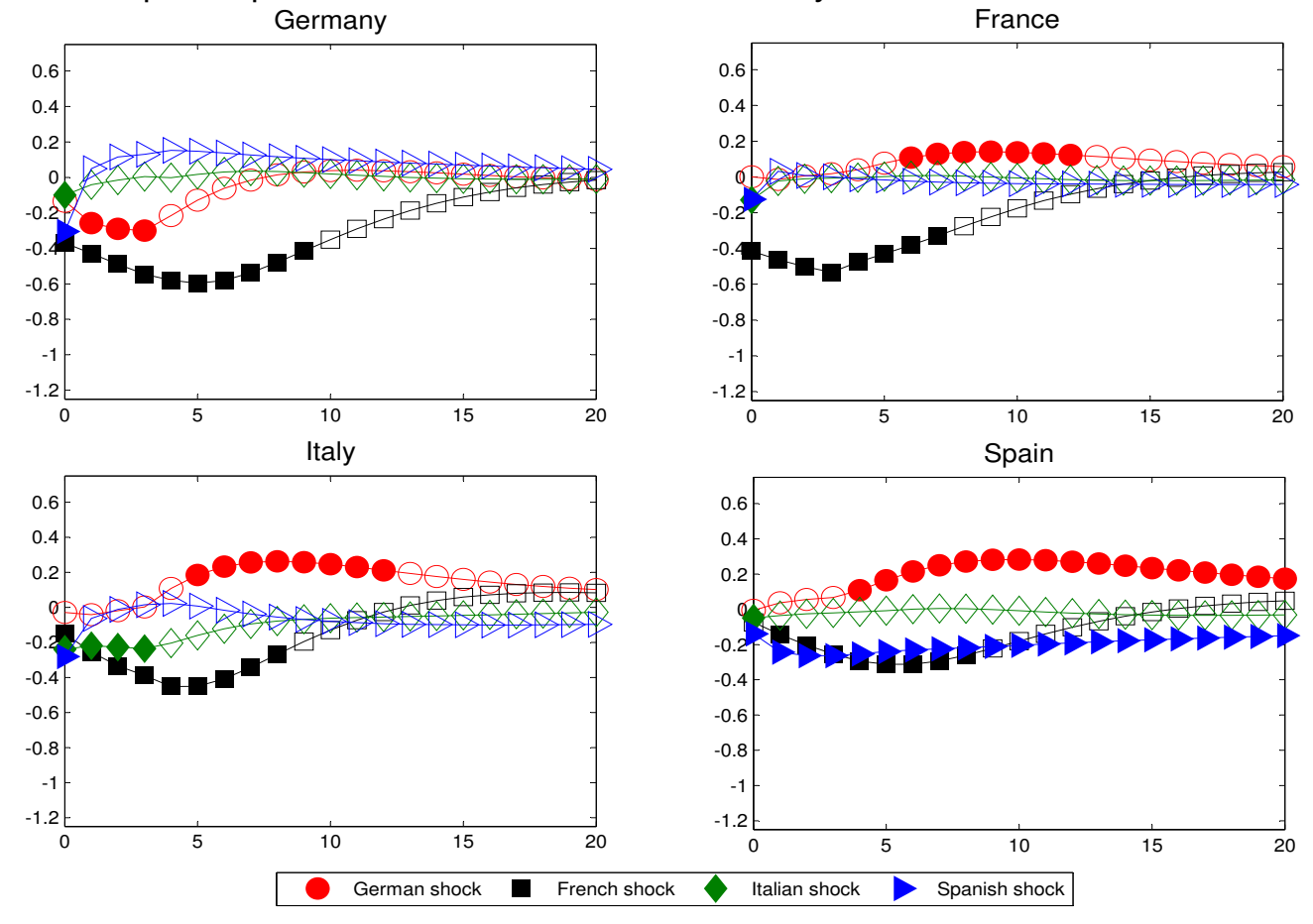

Figure 1: Domestic and cross-border effects of coordinated fiscal shocks (Scenario 1) using an unrestricted $\operatorname{VAR}(1)$ in output and government expenditures. Each of the four graphs include the response of that particular GDP to each of the four coordinated fiscal shocks. Filled markers indicate significant responses at the $68 \%$ level.

As a second benchmark, we estimate a modified multi-country FAVAR with the important difference that bilateral trade and financial variables are no longer included 15 The responses in output following a coordinated domestic fiscal consolidation (Scenario 1) are summarised in Figure 2. First, we again observe that fiscal spillovers are at times larger than the effects of a domestic shock, particularly when looking at the German and Spanish shocks. Furthermore, these two fiscal shocks induce controversial dynamics in their output: each shock results in a large,

\footnotetext{
${ }^{15}$ That would imply that the auxiliary model $(7)$, used for estimating the factors, reduces to $Y_{t}=\Phi Y_{t-1}+$ $\Lambda^{F} F_{t}+v_{t}$.
} 
negative and long-lasting contraction in the domestic economy and a positive and quantitatively similar expansion in the other country. Third, with the exception of temporary contractionary effects on France and Germany, spillovers from an Italian consolidation are mostly insignificant. It is interesting to note that many of the responses obtained using this modified multi-country FAVAR share some similarities with the results of the unrestricted eight-variable VAR(1) described above.

Output responses to coordinated contractionary domestic fiscal shocks
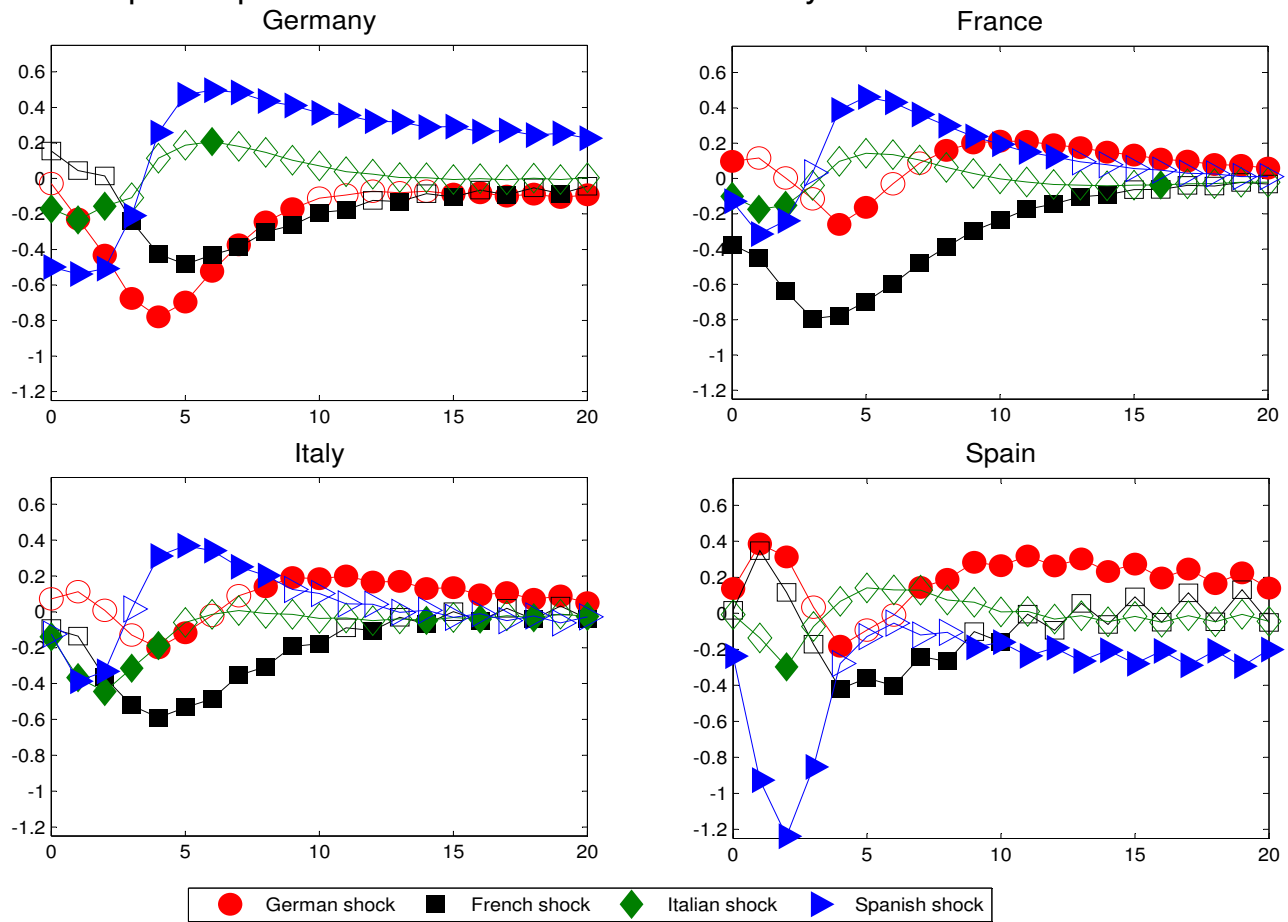

Figure 2: Domestic and cross-border effects of coordinated fiscal shocks (Scenario 1) using a multi-country FAVAR(1) which does not include bilateral trade and financial variables. Each of the four graphs include the response of that particular GDP to each of the four coordinated fiscal shocks. Filled markers indicate significant responses at the $68 \%$ level.

After summarising the output responses to fiscal shocks in a small scale unrestricted VAR and a simplified version of our multi-country model, we now proceed to presenting the results obtained using the multi-country FAVAR model (8).

\subsection{Basic fiscal shocks}

We briefly discuss the responses to our "basic" fiscal shocks before moving to the potentially more interesting policy combinations. Results for Spain (Figure 7), Italy (Figure 8), France (Figure 
9 ) and Germany (Figure 10 following a fiscal expansion are included in Appendix C. First, an expansionary fiscal shock has a positive and persistent impact on the economy implementing the expansionary policy. Domestic GDP, consumption and investment increase for the first eight to ten quarters following the fiscal shock. German output growth, in particular, remains consistently above zero throughout the 20 quarters horizon. Except for a very short lived initial drop in French and German consumption, we do not find evidence of crowding-out effects in the expanding economy. Second, domestic fiscal shocks induce significant albeit qualitatively smaller increases in foreign output.

In order to summarise and more easily compare domestic and foreign induced output effects, we jointly plot the GDP responses in Figure 3 (with the impact response of government expenditure in each country normalised to one). Across all countries, the impact of domestic fiscal policy is consistently larger in comparison to individual, spillover induced effects. The Italian fiscal shock appears to generate relatively long-lived output spillovers, especially on Germany and Spain. Interestingly, the influence that a fiscal consolidation in Italy exerts on the other foreign economies persists even after the response in domestic (i.e. Italian) output dies out. The French fiscal shock has a significant effect on all foreign GDP series during the initial year. Germany also generates temporary spillovers, although the magnitude is quite modest. Particularly in the case of Spain, the influence of the German shock is mostly insignificant.

It is important to note that our basic expansionary fiscal shocks do not eliminate the possibility that government expenditures in the remaining countries comove. Following a Spanish fiscal shock (Figure 7), for example, the increase in domestic spending is coupled with a quantitatively and qualitatively similar pattern in Italian, French and German expenditures. It is hence difficult to disentangle pure, domestically generated effects on the expanding economy from influences induced by the comovement in government spending across countries. It is for this reason that the results using the basic fiscal shocks should be interpreted with care. 
Output responses to basic expansionary domestic fiscal shocks
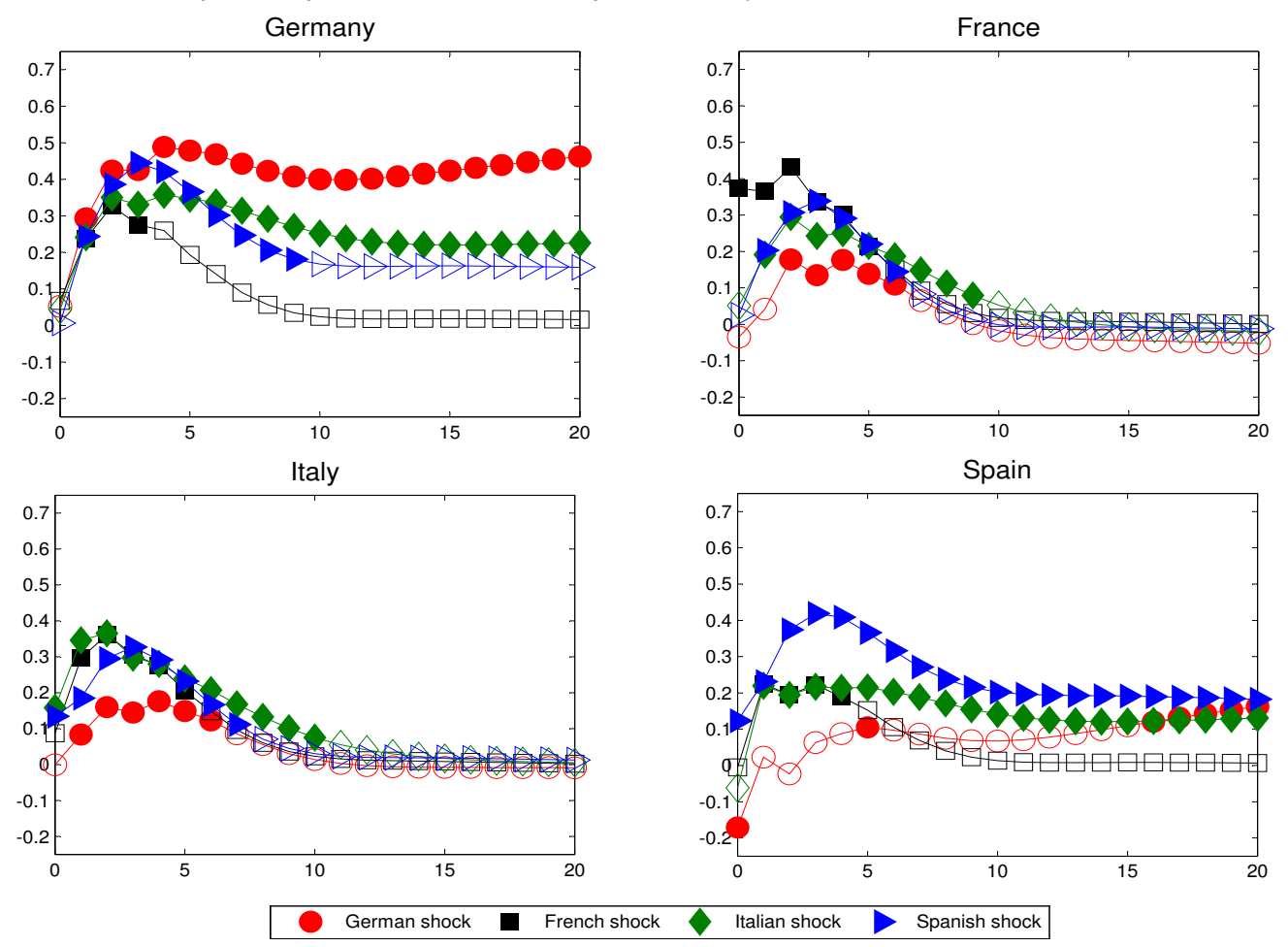

Figure 3: Domestic and cross-border effects of basic fiscal shocks using our multi-country FAVAR. Each of the four graphs include the response of that particular GDP to each of the four basic fiscal shocks. Filled markers indicate significant responses at the $68 \%$ level.

\subsection{Coordinated fiscal shocks}

We now discuss the impulse responses obtained following a coordinated fiscal consolidation (Scenario 1). The graphs summarising the results for each of the four countries included in our analysis can be found in Appendix D.

A Spanish shock (Figure 11) leads to a drop in aggregate activity, consumption and investment. Output does not recover during the 20 quarters following the fiscal shock. The decline in consumption is more short lived and can be explained by a temporary drop in real wages. Confidence falls on impact and its response remains negative for approximately one year. It is interesting to note that the deterioration in economic sentiment is mirrored by an increase in Spanish government bond yields. Fiscal consolidation in Italy (Figure 12) also results in a significant drop in output. The movement in GDP appears to be driven by a decline in private consumption and, more importantly, to a substantial and persistent drop in private investment. Confidence declines on impact but, in contrast to the Spanish case, remains below zero for a prolonged period of time. The fall in confidence is also reflected in higher Italian long-term 
borrowing costs.

The domestic responses in economic activity following a fiscal consolidation in France are summarised in Figure 13 . The temporary decline in GDP can also be mainly attributed to a fall in investment, although the contraction in aggregate activity is shorter lived in comparison to the Italian case. Despite the fall in confidence, however, sovereign yields in France decline. We obtain a similar and qualitatively even larger result on German yields following a government spending cut in Germany (Figure 14). It appears that a fiscal consolidation in the core countries is perceived differently by the bond market when compared to the peripheral economies. Nonetheless, the German shock induces significant and long lasting effects on German GDP.

We summarise the effects of coordinated fiscal consolidations on output in one compact graph (Figure (4). We observe that economic activity consistently reacts stronger to a domestic consolidation than to a foreign fiscal shock ${ }^{16}$ The puzzling result of proportionally larger spillover effects obtained using the two simplified models in Section 5.1 and obtained by Hebous and Zimmermann (2013) using the GVAR appears to have disappeared. Cross-border spillovers are heterogenous and depend on where the fiscal shock originates as well as on the foreign country considered. Spain and Italy have a significant albeit short lived influence on German GDP, although delayed, second round effects do re-emerge two years after an Italian shock. The Spanish shock, in particular, appears to induce a strong, negative influence on foreign output. Note that the counterintuitive dynamics between the Spanish and German GDP obtained in Section 5.1 are now no longer detected. Similar spillovers are generated on the French economy: the Italian fiscal shock has a negative and even more persistent impact than on Germany and spillovers from Spain are, again, large and significant during the first four quarters. One reason behind the distinct influence of a Spanish shock can be traced back to the dynamics of confidence in Figure 11. the fiscal consolidation induces a strong instantaneous decline in the economic sentiment indicator across all countries and the deterioration in the ESI lasts for one year in Spain, France and Germany. This comovement appears to be connected to the significant but short lived joint decline in output levels. Our findings suggest that confidence may play a role in the transmission of fiscal policy not only domestically, as recently investigated by Bachmann and Sims (2012), but also across borders. Spillovers from a German fiscal shock are, maybe surprisingly, mostly insignificant ${ }^{17}$ With the exception of delayed significant responses of investment and

\footnotetext{
${ }^{16}$ In the identification of each domestic fiscal shock, the government expenditures in the remaining countries are restricted not to move. Consequently, the size of the response in GDP to a fiscal consolidation can be interpreted as a multiplier.

${ }^{17}$ When looking at spillover effects on Spain, we observe that output initially increases in response to a German fiscal consolidation, a result we also obtained when disregarding cross-border variables in Section 5.1 The positive effect on Spanish GDP is, however, smaller, less persistent and switches its sign towards the end of the response
} 
government expenditure in Spain and France (see Figure 14, GDP and its components remain unaffected in all countries. What is interesting is that the fall in economic sentiment in the contracting country (Germany) does not, in this case, feed back into lower levels of confidence in the remaining three economies. This further supports the hypothesis that the confidence channel may offer valuable insights into the propagation of fiscal policy shocks.

\section{Output responses to coordinated contractionary domestic fiscal shocks}
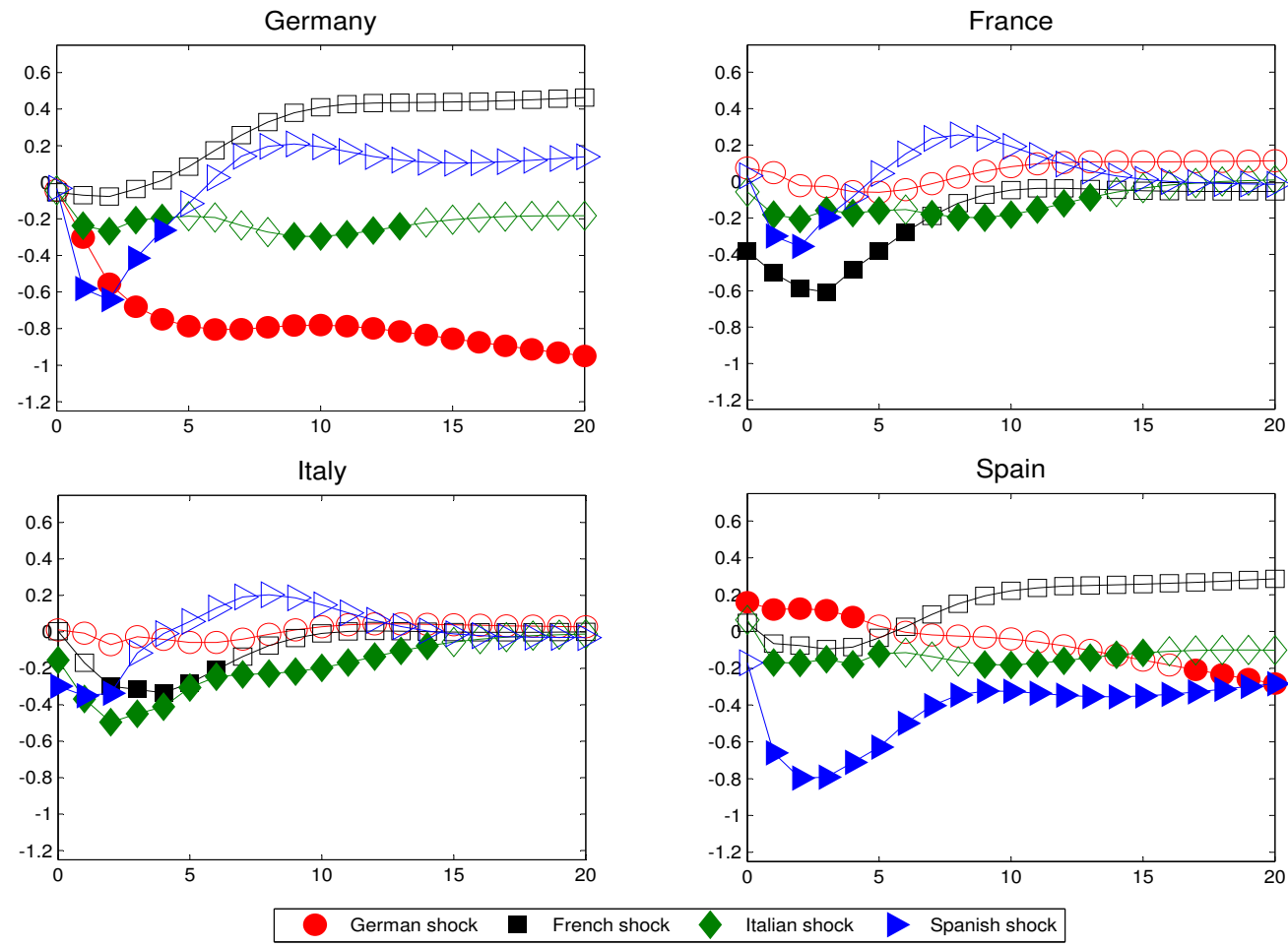

Figure 4: Domestic and cross-border effects of coordinated fiscal shocks (Scenario 1) using our multicountry FAVAR. Each of the four graphs include the response of that particular GDP to each of the four coordinated fiscal shocks. Full shapes indicate significant responses at the $68 \%$ level.

The linear combination of domestic fiscal shocks that jointly decreases government spending in Spain and Italy during four consecutive quarters while keeping expenditure in Germany and France unchanged (Scenario 2) results in the impulse responses in Figure 5. First, we observe that output, consumption and investment decline in Italy and Spain. Crucially, the negative effects on output in these two countries are more pronounced when both economies engage in a process of fiscal consolidation at the same time. Aggregate activity in Spain, in particular, does not recover in the 20 quarters following the shock and the combined output loss is higher than when compared to Figure 11. Italy experiences a stronger decline in the first year but, window. 
surprisingly, recovers quicker than in Figure 12. Second, the fall in the three price/cost indicators is relatively large and permanent. Third, we again obtain a temporary decline in confidence levels coupled with an even larger and more persistent increase in government bond yields.

The coordinated spending consolidation also results in important cross border effects. With the exception of insignificant contemporaneous reactions, we observe a decline in French and German output and private consumption for approximately one year. Investment is generally unaffected. The magnitude of output spillovers during these four quarters is larger than those observed in Figures 11, Figure 12 and summarised by Figure 4. Confidence strongly declines on impact across all countries but the response quickly becomes insignificant. A relatively puzzling finding is that economic sentiment in Italy recovers much faster when Spain also engages in a process of fiscal consolidation. The recovery in confidence following a strong initial drop is consistent with the larger but less persistent domestic and cross border output effects. For example, German GDP, government expenditure, private investment, and ESI no longer experience the double-dip contraction highlighted in Figures 12 and 4 (green diamond markers).

Policy Scenario 3 is defined as a linear combination in all four basic fiscal shocks which generates an increase in government expenditure in the North by one percent for four quarters coupled with a decline in spending in the South (Figure 6) 18 The responses in Italian output and investment are negative for the first four quarters following the shock but become insignificant thereafter. The magnitude of the decline in Italian GDP is smaller and the downturn is shorter lived than the one highlighted in Figure 5. For Spain, we observe that aggregate economic activity and private investment decline at a similar pace as under Scenario 2. An important difference, however, is that private consumption is no longer affected in either of the two peripheral countries with the exception of a temporary decline in Spain in the initial two quarters. When looking at the responses of France and Germany, we observe that investment increases for the first two years. Most surprisingly, aggregate activity no longer moves in response to a fiscal expansion in the core economies. We even observe a short lived decline in French consumption. Spillovers from the contractionary fiscal policy implemented in the South appear to counteract the positive output effects highlighted by Figure 3 Confidence, again, appears to play an important role. The economic sentiment indicator in Germany does not increase in response to an expansionary fiscal policy when Italy and Spain are hit by a negative fiscal shock. This comes in contrast to the strong, positive relationship between German GDP and

\footnotetext{
${ }^{18}$ It would be imprecise to call such a coordinated shock a union-wide "balanced-budget" policy scenario. One would need to trace the actual effects that the $1 \%$ change generates on expenditures in each country. Under some assumptions, it could be possible to define more accurate weights in the linear combination which leaves total expenditures unchanged.
} 
ESI observed in Figure 14.

GDP Germany

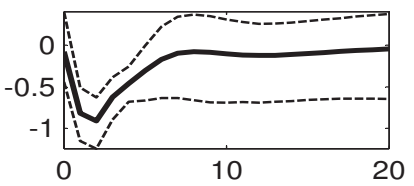

Consumption Germany

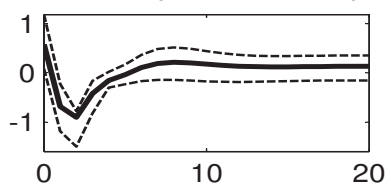

Investment Germany

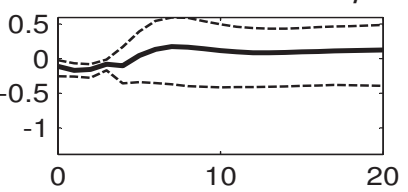

Guv Expend. Germany

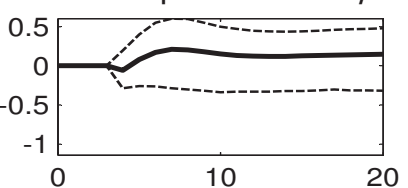

Real Wages Germany

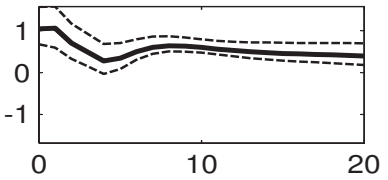

ULС Germany

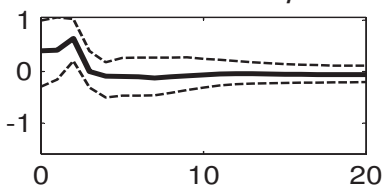

HCPI Germany

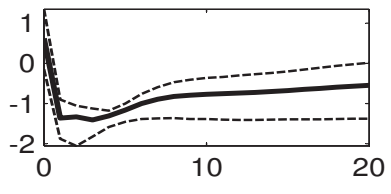

Gav Bands Germany
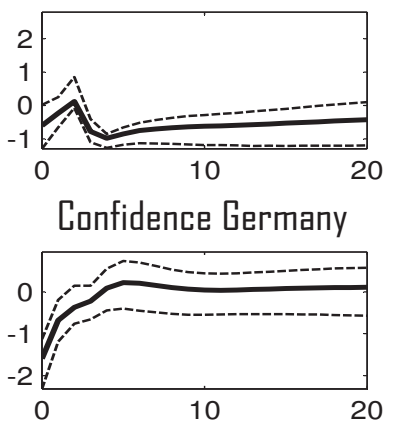

GDP France

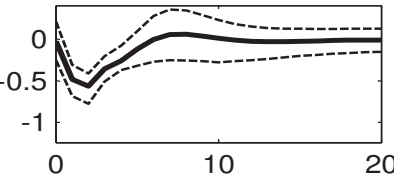

Consumption France

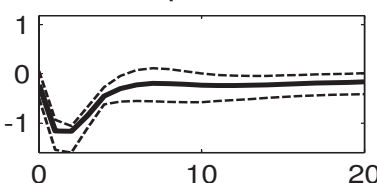

Investment France

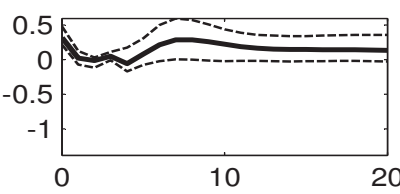

Gov. Expend. France

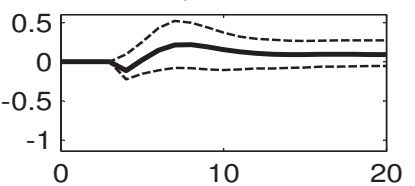

Real Wages France
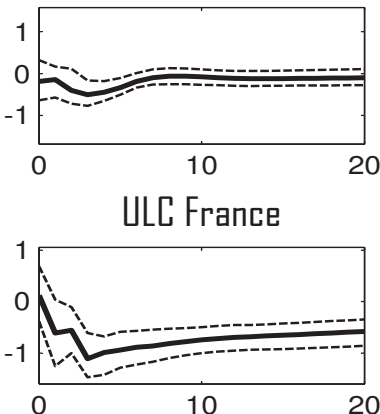

НСPI France

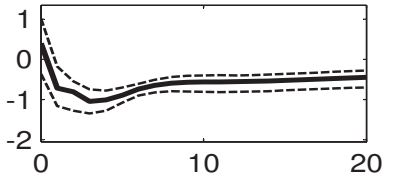

Gov Bonds France

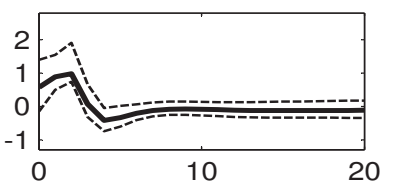

Confidence France

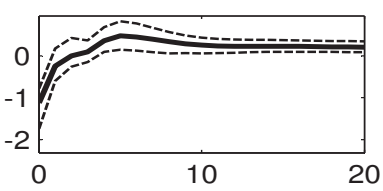

GDP Italy

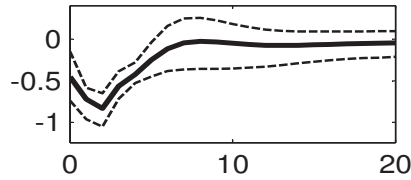

Consumption Italy

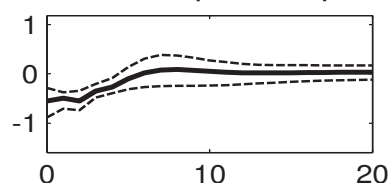

Investment Italy

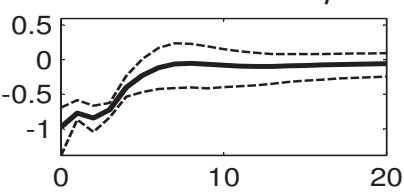

Guv. Expend. Italy

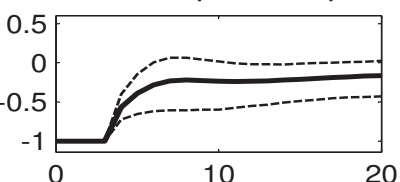

Real Wages Italy

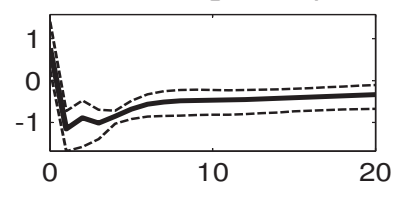

ULC Italy

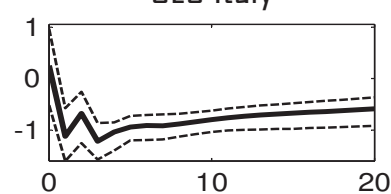

HCPI Italy

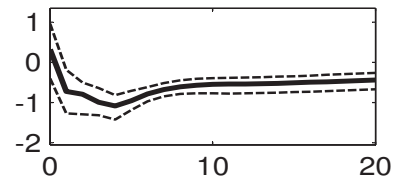

Gav Bands Italy

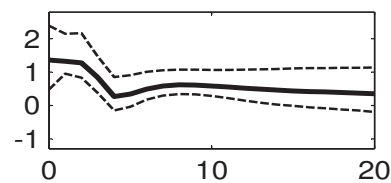

Confidence Italy

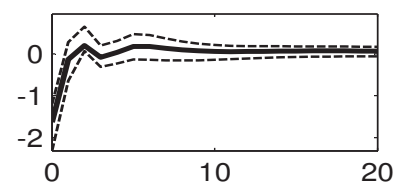

GDP Spain

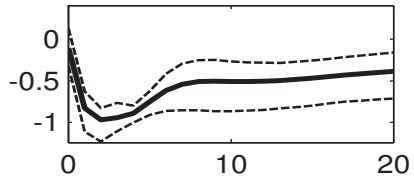

Consumption Spain

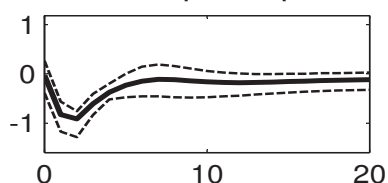

Investment Spain

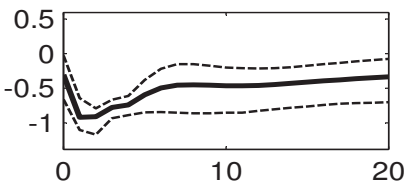

Gov. Expend. Spain

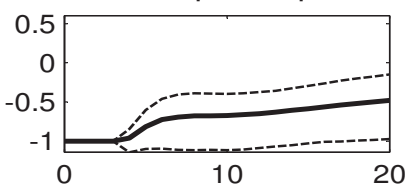

Real Wages Spain
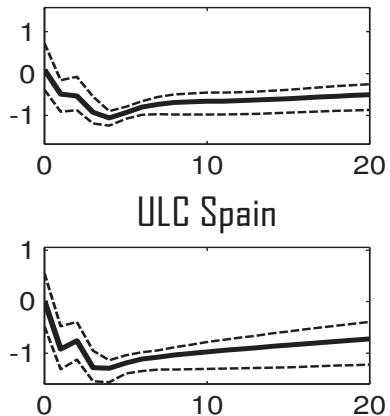

HCPI Spain

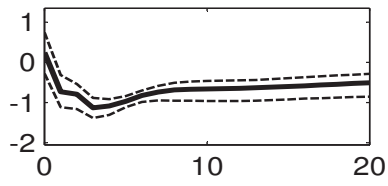

Guv Bonds Spain

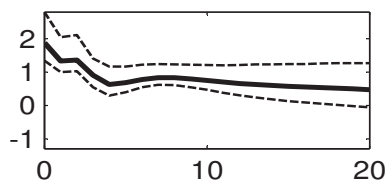

Confidence Spain

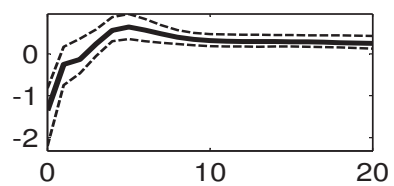

Figure 5: Coordinated Spending Shock: Southern Europe. Impulse responses with 68\% CI 
GDP Germany

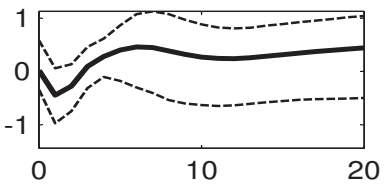

Consumption Germany

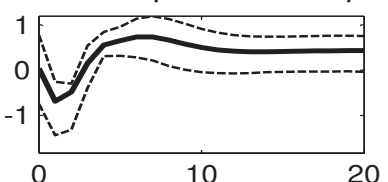

Investment Germany

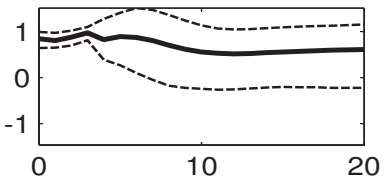

Gov Expend. Germany

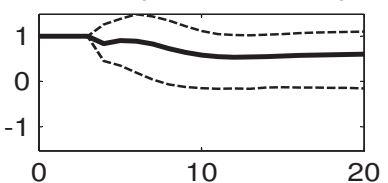

Real Wages Germany
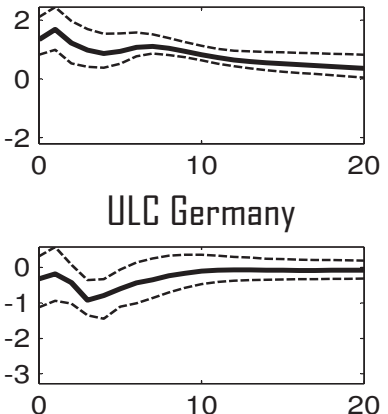

HСPI Germany

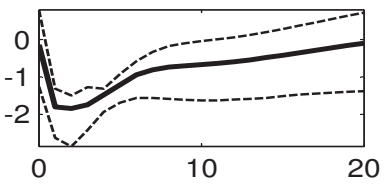

Gov Bonds Germany

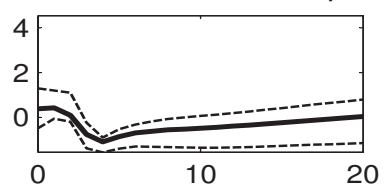

Canfidence Germany

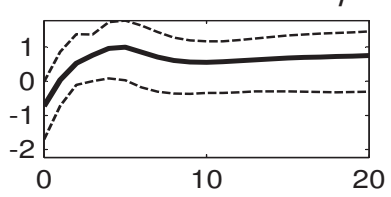

GDP France

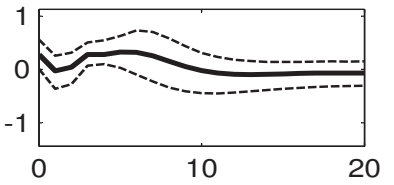

Consumption France

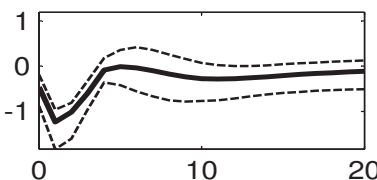

Investment France

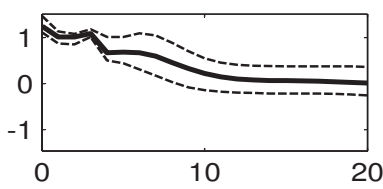

Gov. Expend. France

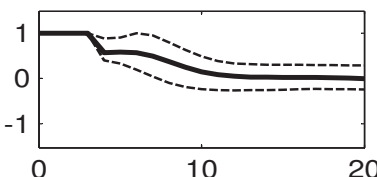

Real Wages France

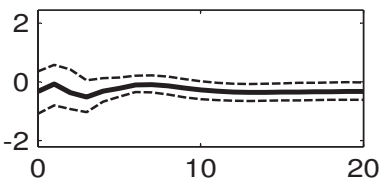

ULC France

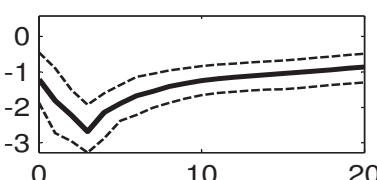

HCPI France

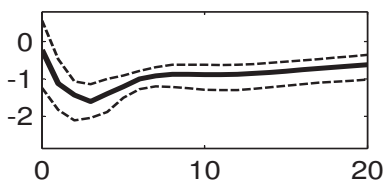

Gov Bonds France

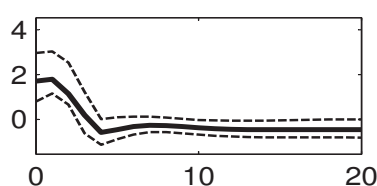

Confidence France

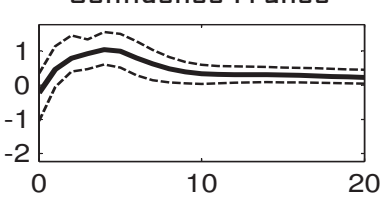

GDP Italy

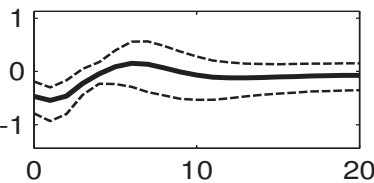

Consumption Italy

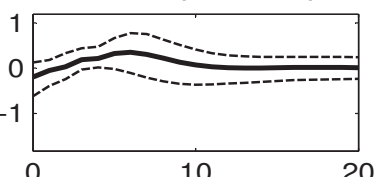

Investment Italy

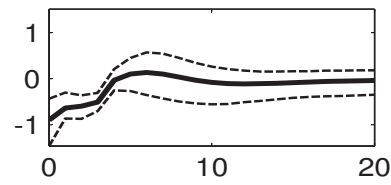

Gov. Expend. Italy

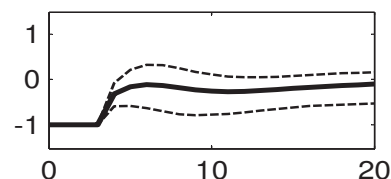

Real Wages Italy
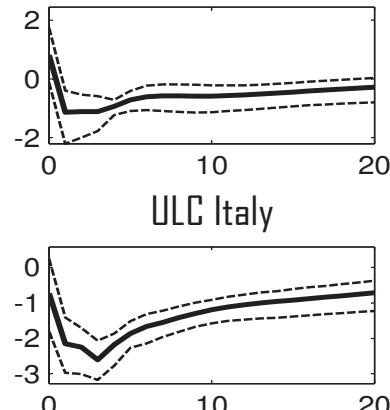

HCPI Italy

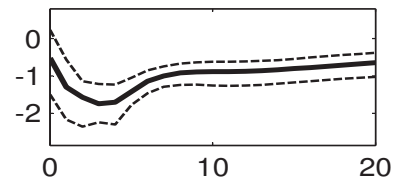

Gov Bonds Italy

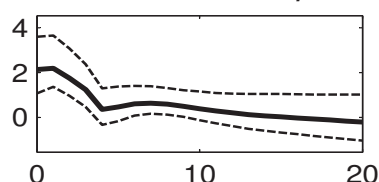

Canfidence Italy

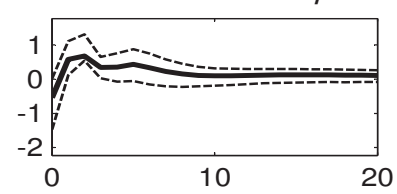

GDP Spain

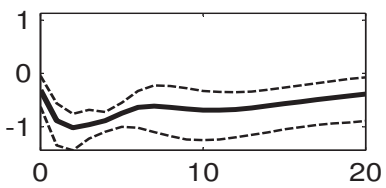

Consumption Spain

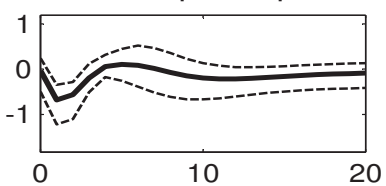

Investment Spain

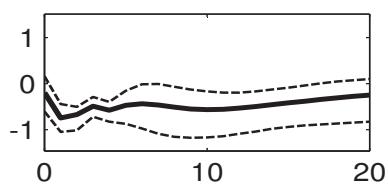

Gov. Expend. Spain

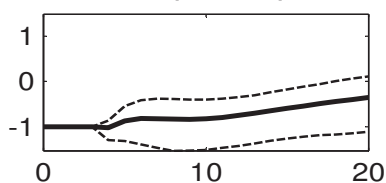

Real Wages Spain
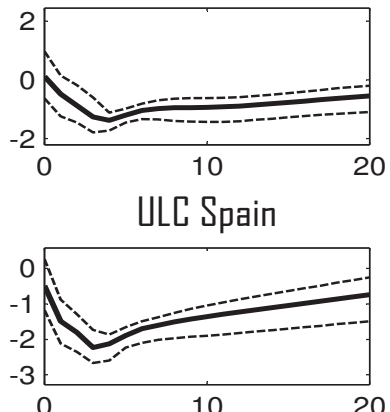

HСPI Spain

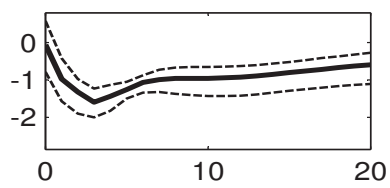

Gav Bands Spain

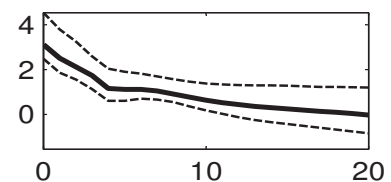

Confidence Spain

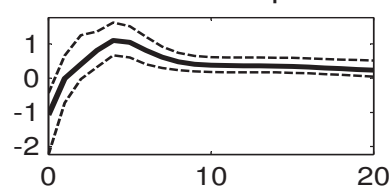

Figure 6: Coordinated Spending Shock: North-South Balanced. Impulse responses with 68\% CI 


\section{Conclusion}

Since the start of the financial crisis in 2008, researchers and policy-makers have shown renewed interest in the role of fiscal policy. While there is a large literature dealing with the impact of fiscal policy in closed economies, very few authors address the issue of cross-border effects of fiscal shocks (Hebous and Zimmerman, 2012, 2013, Auerbach and Gorodnichenko, 2013). Recent empirical papers have relied on a number of simplifying assumptions in their modelling approach, either by limiting the number of cross-sectional units, restricting the channels of interdependence, imposing cross-sectional homogeneity or disregarding feedback effects across units. Our contribution to the growing literature of cross-border effects of fiscal policy is threefold. First, we propose a multi-country FAVAR model with both observable and unobservable factors by combining the multi-country VAR approach of Canova and Ciccarelli (2009) with the FAVAR framework of Bernanke et al. (2005). Second, we extract information from both domestic and cross-border variables that, according to economic theory, are expected to be relevant for identifying the effects of fiscal policy. Using macroeconomic and fiscal aggregates from the four largest Eurozone countries (Germany, France, Italy, Spain) as well as variables capturing cross-border linkages, we investigate the domestic and cross-border effects of country specific government expenditure shocks. Third, we pay particular attention to the identification of (structural) fiscal policy interventions. To this aim, we use a more agnostic, sign restriction based identification approach. By linearly combining the identified country specific fiscal shocks we are also able to trace the effects of coordinated policy scenarios.

We find negative and significant effects of fiscal consolidations on domestic output, private investment and consumption for all countries. Domestic multipliers range between 0.5 for Italy and 1 for Germany and never surpass unity. Cross-border spillovers are heterogenous and depend on where the expenditure shock originates as well as on the foreign country considered. Importantly, economic activity consistently reacts stronger to a domestic consolidation than to a foreign fiscal shock. Our results indicate that a negative Italian shock leads to significant and persistent decline in German, French and Spanish output. A Spanish consolidation induces a quantitatively larger but shorter-lived decline in foreign output. Spillovers following a negative fiscal policy shock in France are, maybe surprisingly, mostly insignificant. We compare our results with two benchmark, simplified multi-country models: an unrestricted VAR in output and government consumption and a multi-country FAVAR which does not include bilateral trade and banking flow variables. We observe several puzzles in the magnitude and sign of the GDP response to domestic and foreign fiscal shocks. Most of the counterintuitive dynamics no longer emerge in our final multi-country FAVAR and we obtain reasonable domestic and cross-border 
multipliers.

We further find that coordinated spending cuts in the periphery induce significant, albeit shorter lived output spillovers. The negative impact on foreign GDP in the first year following a joint consolidation is larger compared to when government expenditures decline in Italy or Spain only. The magnitude of cross-border spillovers never surpasses domestic multipliers, in contrast to the unreasonably large foreign induced effects obtained by Hebous and Zimmermann (2013). Although the sample is different and a direct comparison may not be appropriate, our spillover effects are also much smaller than those obtained by Auerbach and Gorodnichenko (2013). We also investigate the possibly relevant policy scenario of a fiscal contraction in the South coupled with a fiscal expansion in the North. The response of economic activity in Germany and France is now mostly unaffected by the increase in government expenditure. It appears that spillovers from the contractionary fiscal policy implemented in the South counteract the expansionary aggregate demand effects in the North. Spain and Italy continue to experience a downturn, with the important difference that private consumption in both peripheral countries is no longer affected.

Our findings suggest that confidence may play a role in the transmission of fiscal policy not only domestically, as recently investigated by Bachmann and Sims (2012), but also across borders. Systematic movements in confidence may convey important insights into the response of aggregate economic activity. A domestic fiscal consolidations is generally reflected in a significant, instantaneous decline in domestic economic sentiment. Only when confidence levels in a foreign country comove with confidence in the economy where the fiscal shock originates are spillovers significant. A second interesting finding is the inverse relationship between sovereign bond yields and confidence in Spain and Italy. There is a contrasting bond market reaction with respect to the core and peripheral countries: while Spanish and Italian yields increase in response to a domestic fiscal consolidation, French and German borrowing costs generally decline or remain unaffected.

A first important extension to our model is controlling for the stance of monetary policy. The effect of fiscal policy derived from different theoretical models can be highly sensitive to whether monetary policy is accommodative or contractionary. However, identifying monetary policy shocks and their effects on macroeconomic and financial aggregates is a complex issue in itself. Moreover, we believe that the losses from disregarding monetary policy should be limited. In a monetary union, the central bank cannot increase or decrease its policy rate in response to country specific economic developments and the policy stance is common across the region. Therefore, regardless of the prevailing policy rate at the union level, the relative monetary policy 
between any two countries is fixed. Second, possible non-linear effects of fiscal policy could be introduced in this multi-country FAVAR by defining further factors. Third, we believe that the interesting relationship between fiscal shocks, confidence and output merits further work. Barsky and Sims (2012) highlight that innovations in confidence largely reflect information about future economic fundamentals and productivity shocks. This suggests that fiscal policy targeted towards (productive) government investments may be more strongly related to a systematic response in confidence (Bachman and Sims, 2012). It may therefore be relevant to further separate our aggregated government expenditure variable into its two main components: final consumption expenditure and investments. 


\section{References}

[1] Auerbach, A. J. and Gorodnichenko, Y. (2013). Output spillovers from fiscal policy. American Economic Review 103(3), 141-46.

[2] Bachmann, R. and Sims, E. R. (2012). Confidence and the transmission of government spending shocks. Journal of Monetary Economics 59(3), 235-249.

[3] Bai, J. and Ng, S. (2002). Determining the Number of Factors in Approximate Factor Models. Econometrica 70(1), 191-221.

[4] Banbura, M., Giannone, D. and Reichlin, L. (2010). Large Bayesian Vector Auto Regressions (2010). Journal of Applied Econometrics 25, 71-92.

[5] Barsky, R. and Sims, E. (2012). Information, animal spirits and the meaning of innovations in consumer confidence. American Economic Review 102(4), 1343-1377.

[6] Beetsma, R. (2008). A survey of the effects of discretionary fiscal policy. Policy Report.

[7] Beetsma, R and Guiliodori, K. (2006). Trade spillovers of Fiscal Policy in the European Union: A Panel Analysis. Economic Policy 21(48), 639-687.

[8] Beetsma, R. and Guiliodori, K. (2011). The effects of government purchase shocks: review and estimates for the EU. The Economic Journal 121(550), F4-F32.

[9] Bernanke, B., Boivin, J. and Eliasz, P. (2005). Measuring the effects of monetary policy: a factor-augmented vector autoregressive (FAVAR) approach. The Quarterly Journal of Economics 120(1), 387-422.

[10] Bénassy-Quéré, A. and Cimadomo, J. (2007). Changing Patterns of Domestic and CrossBorder Fiscal Policy Multipliers in Europe and the US. CEPII Working Paper.

[11] Benetrix, A. S. and Lane, P. R. (2013). Fiscal shocks and the real exchange rate. International Journal of Central Banking 9(3), 6-37.

[12] Bicu, A. and Candelon, B. (2103). On the importance of indirect banking vulnerabilities in the Eurozone. Journal of Banking and Finance 37, 5007-5024.

[13] Blanchard, O. and R. Perotti (2002). An Empirical Characterisation of the Dynamic Effects of Changes in Government Spending and Taxes on Output The Quarterly Journal of Economics 117(4), 1329-1368. 
[14] Brunnermeier, M., De Gregorio, J., Eichengreen, B., El-Erian, M., Fraga, A., Ito, T., Lane, P. R., Pisani-Ferry, J., Prasad, E., Rajan, R., Ramos, M., Rey, H., Rodrik, D., Rogoff, K., Song Shin, H., Velasco, A., Weder di Mauro, B., and Yu, Y. (2012). Banks and CrossBorder Capital Flows: Policy Challenges and Regulatory Responses, Brookings Committee on International Economic Policy and Reform.

[15] Canova and Ciccareli (2009). Estimating multi-country VAR models. International Economic Review 50(3), 929-959.

[16] Canova and Ciccareli (2013). Panel Vector Autoregressive Models: A Survey. Centre for Economic Policy Research.

[17] Corsetti, G., Meier, A. and Müller, G. J. (2010). Cross-Border Spillovers from Fiscal Stimulus. International Journal of Central Banking 6(1), 5-37.

[18] Corsetti, G. and Müller, G. J. (2007). Twin Deficits, Openness and the Business Cycle, Journal of the European Economic Association, Papers and Proceedings 6, 404-413.

[19] Dees, S., di Mauro, F., Pesaran, M. H., Smith, L. V. (2007). Exploring the international linkages of the euro area: a global VAR analysis. Journal of Applied Econometrics 22, 1-38.

[20] De Grauwe, P. and Ji, Y (2012). Mispricing of Sovereign Risk and Macroeconomic Stability in the Eurozone. Journal of Common Market Studies 50(6), 866-880.

[21] De Mol, V., Giannone, D. and Reichlin, L. (2008). Forecasting using a large number of predictors: is Bayesian shrinkage a valid alternative to principal components? Journal of Econometrics 146(2), 318-328.

[22] Forni, M., Hallin, M., Lippi, M. and Reichlin, L. (2000). The generalised dynamic-factor model: Identification and estimation. Review of Economics and statistics 82 (4), 540-554.

[23] Forni, M., Hallin, M., Lippi, M. and Reichlin, L. (2005). The generalised dynamic factor model. Journal of the American Statistical Association 100(471), 830-840.

[24] Goncalves, S., and Perron, B. (2014). Bootstrapping factor-augmented regression models. Journal of Econometrics 182(1), 156-173.

[25] Hebous, S. and Zimmermann, T. (2012). Cross-Border Effects of Fiscal Consolidations: Estimates Based on Narrative Records. Working paper series SSRN.

[26] Hebous, S. and Zimmermann, T. (2013). Estimating the effects of coordinated fiscal actions in the euro area. European Economic Review 58, 110-121. 
[27] Kock, A.B. and Callot, L. (2015). Oracle inequalities for high dimensional vector autoregressions. Journal of Econometrics 186, 325-344.

[28] Krugman, P. (2008). The international finance multiplier. Mimeo, Princeton University.

[29] Moon, H. R., Schorfheide, F. and Granziera, E.(2013). Inference for VARs Identified with Sign Restrictions. Mimeo, University of Southern California.

[30] Mountford, A. and Uhlig, H. (2009). What are the effects of fiscal policy shocks? Journal of Applied Econometrics 24, 960-992.

[31] Nakamura, E. and Steinsson, J. (2014). Fiscal stimulus in a monetary union: evidence from US regions. American Economic Review 104(3), 753-792.

[32] Pesaran, M.H., Schuermann, T., Weiner, S.M. (2004). Modelling regional interdependencies using a global error correcting macroeconometric model. Journal of Business and Economic Statistics 22, 129-162.

[33] Pesaran, M.H. and Shin, Y. (1998). Generalized impulse responses in linear multivariate models. Economics Letters 58(1), 17-29.

[34] Uhlig, H. (2005). What are the effects of monetary policy on output? Results from an agnostic identification procedure. Journal of Monetary Economics 52, 381-419.

[35] Yamamoto, Y. (2012). Bootstrap Inference for Impulse Response Functions in FactorAugmented Vector Autoregressions. Manuscript, Hitotsubashi University. 


\section{Appendix A}

In this Appendix we summarise the time series used in the empirical analysis, specifying the exact variable name, code (if available), database and source. All series are quarterly, 1999:Q1 to 2012:Q4. We use seasonally adjusted data and, when not available, we applied a Census X-12 adjustment method on the raw data.

Output: Gross Domestic Product - Expenditure Approach (B1_GE), Quarterly National Accounts, OECD.

Consumption: Private final consumption expenditure (P31S14_S15), Quarterly National Accounts, OECD.

Investment: Gross fixed capital formation (P51), Quarterly National Accounts, OECD.

Government Expenditure: General government final consumption expenditure $(P 3)$ plus Government gross capital formation (D.5), Government Statistics, Eurostat.

Price and competitiveness: Real Wages, Unit Labour Costs, Harmonised Consumer Price Index - all items, Main Economic Indicators, OECD.

Confidence: Economic Sentiment Indicator (BS_ESI_I), Eurostat.

Sovereign bond yields: Long-term government bond yields - 10 year, Main Economic Indicators, OECD.

Trade: Bilateral exports (BDQ7D0FRA, BDQ7D0ITA, BDQ7D0ESA, FRQ7D0BDA, FRQ7D0ITA, FRQ7D0ESA, ITQ7D0BDA, ITQ7D0FRA, ITQ7D0ESA, ESQ7D0FRA, ESQ7D0BDA, ESQ7D0ITA), Direction of Trade Statistics, IMF.

Financial claims: Consolidated claims - immediate borrower basis, Consolidated banking statistics, BIS 


\section{Appendix B}

In this Appendix we give a brief outline of the estimation strategy as well as a more detailed description of the penalty function approach for the identification of structural shocks.

\section{Estimation}

Let $y_{i, t}$ be a $K$ dimensional column vector containing domestic variables of country $i$, and $F_{t}$, of dimension $r \times 1$, a series of latent factors summarising a large amount of information. We assume that the joint dynamics of $Y_{t}=\left[y_{i, t}^{\prime}, \ldots, y_{N, t}^{\prime}\right]^{\prime}$ and $F_{t}$ can be represented by the following multivariate autoregression (multi-country FAVAR model):

$$
\left[\begin{array}{l}
Y_{t} \\
F_{t}
\end{array}\right]=\left[\begin{array}{ll}
A & B \\
C & D
\end{array}\right]\left[\begin{array}{l}
Y_{t-1} \\
F_{t-1}
\end{array}\right]+\left[\begin{array}{c}
w_{y, t-1} \\
w_{f, t-1}
\end{array}\right]
$$

where $A, C$ are parameter matrices which obey a pre-imposed structure while $B$ and $D$ are unrestricted. More specifically, as mentioned in the text, $A$ and $C$ can be expressed as linear combinations of loadings related to observable factors. The fact that $A$ and $C$ can be expressed in terms of linear combinations of a small number of underlying parameters makes the estimation of (8) particularly easy, since the model can be expressed in terms of a linearly restricted VAR. For this purpose we can write (8) in SUR form as

$$
z_{t}=\left(z_{t-1} \otimes I_{K N r}\right) \Omega \theta
$$

where $z_{t}=\operatorname{vec}\left(\left[Y_{t}^{\prime} F_{t}^{\prime}\right]^{\prime}\right)$ and $\Omega$ is a predetremined selection matrix which linearly combines the loadings in $\theta$, such that $\Omega \theta=\operatorname{vec}\left(\left[\begin{array}{ll}A & B \\ C & D\end{array}\right]\right)$. The parameter vector $\theta$ can be (efficiently) estimated by regressing $z_{t}$ on $\left(z_{t-1} \otimes I_{K N r}\right) \Omega$ by (two-stage) GLS.

Since $F_{t}$ is unobserved we need to estimate it first. To this aim, consider the auxiliary model

$$
\begin{aligned}
Y_{t} & =\phi Y_{t-1}+\Lambda_{1}^{F} F_{t}+v_{y, t} \\
X_{t} & =\Lambda_{2}^{F} F_{t}+v_{x, t}
\end{aligned}
$$

where $X_{t}$ is the set of variables releated to bilateral linkages. The auxiliary model in 10 and (11) reveals the interpretation of the latent factors in $F_{t}$ : they summarise the information not captured by the observable factor model of $Y_{t}=\phi Y_{t-1}$ (implied by the parametrisation of $\phi$ ) and the information contained in $X_{t}$.

Conditional on $\Lambda_{1}^{F}$ and $F_{t}, \phi$ can be estimated by GLS in a similar way as $(9)$ and, conditional on $\phi$, the latent factors $F_{t}$ and their loadings $\Lambda_{1}^{F}, \Lambda_{2}^{F}$, can be estimated by principal components. 
The number of latent factors can be determined by standard model selection criteria (see e.g. Bai and Ng, 2002). Applying a variety of criteria suggested in the literature, we find that in our analysis two factors are sufficient to summarise the information 19

Instead of imposing identifying restrictions to estimate (10)-(11) jointly, we iteratively estimate $\phi$ by GLS and $F_{t}, \Lambda_{1}^{F}$, and $\Lambda_{2}^{F}$ by principal components until convergence.

Since the number of time series observations is relatively small, the bootstrap might be superior to inference constructed based on asymptotic arguments. The bootstrap in factor augmented regressions has recently been shown to be asymptotically valid in Goncalves and Perron (2014). To construct confidence intervals for the impulse responses we implement the residual-based bootstrap algorithm proposed by Yamamoto (2012).

\section{The penalty function}

We deviate from the identification approach proposed in Mountford and Uhlig (2009) in two respects. First, we identify all shocks simultaneously (and not sequentially) and we use a different penalty function. We believe that the sequential identification is too restrictive since it constraints the parameter space of shocks identified in a subsequent stage, which cannot be easily motivated in our setting. Second, we use a slightly different functional form of the penalty function. More precisely, the criterion to be maximised over $\left[q_{1}, \ldots, q_{S}\right]=: Q \in \mathcal{V}_{S}\left(\mathbb{R}^{K N+r}\right)$, which corresponds to the set of all orthonormal $S$-frames in $\mathbb{R}^{K N+r}$, is given by

$$
\mathcal{Q}\left(q_{1}, . ., q_{S}\right)=\sum_{s \in S} \sum_{p \in P_{s}} V_{s}^{-1} \sum_{v \in V_{s}} g\left(a^{s, p, v} \cdot q_{s}\right),
$$

where $S$ corresponds to the total number of shocks to be identified, $P_{s}$ denotes the number of periods a particular shock is restricted to follow the imposed sign, and $V_{s}$ is the number of variables a particular shock is assumed to affect. The row vector $a^{s, p, v}$ corresponds to the associated row in the respective orthogonalised MA coefficient, transformed such that possibly negative sign restrictions are translated into positive ones. The weight $V_{s}^{-1}$ is needed to give equal weight to every shock, independent of the number of variables restricted. The penalty function $g(x)$ is chosen such that it is twice continuously differentiable and gradient based optimisation algorithms can be used. More specifically, we assume $g(x)=100\left(x^{2} \operatorname{sgn}(x)+x^{2}\right)$.

\footnotetext{
${ }^{19}$ The results shown in the paper refer to the model estimated with two factors. The results do not change qualitatively when choosing either two or three factors. Note also, that increasing the number of factors leads to an over-proportional increase in the number of parameters to be estimated in the final model in 8 .
} 


\section{Appendix C: Basic expansionary fiscal shocks}

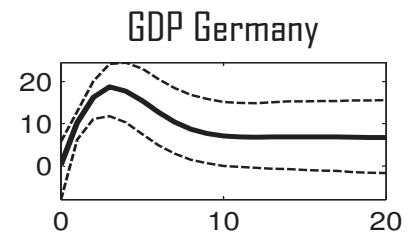

Consumption Germany
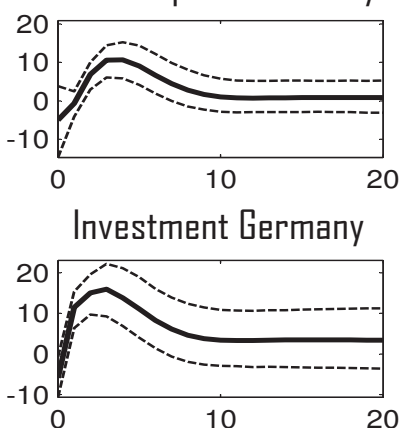

Gov Expend. Germany

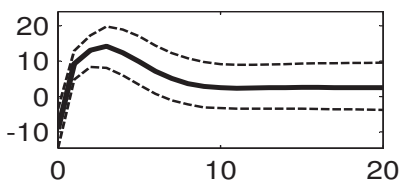

Real Wages Germany

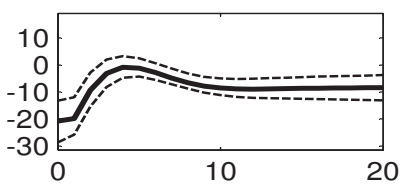

ULC Germany

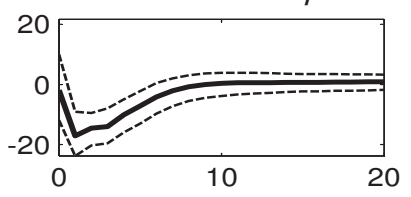

HСPI Germany

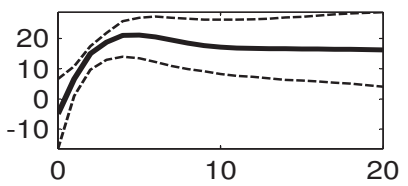

Guv Bands Germany

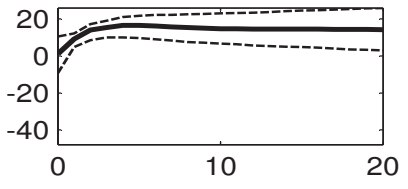

Confidence Germany

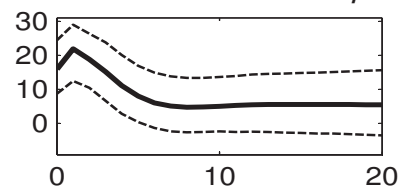

GDP France

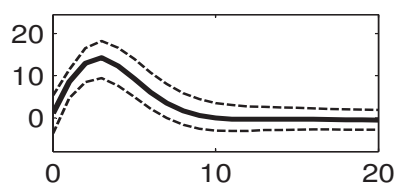

Consumption France
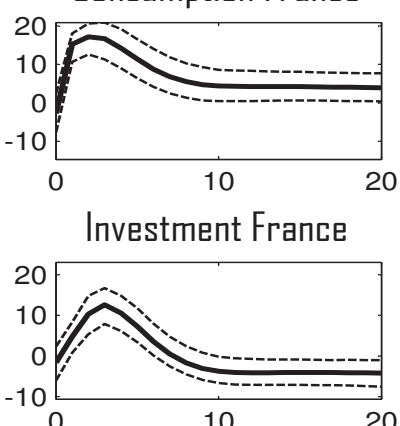

Gov. Expend. France

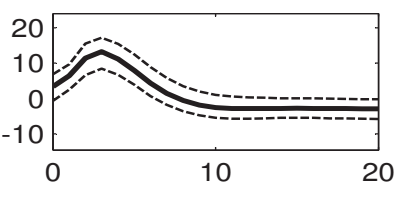

Real Wages France

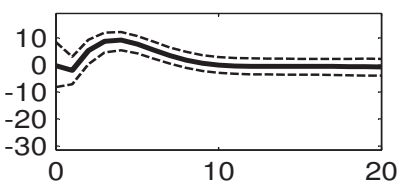

ULC France

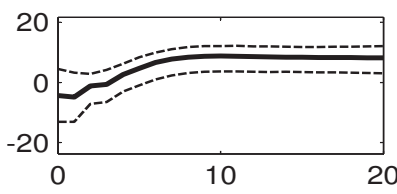

HCPI France

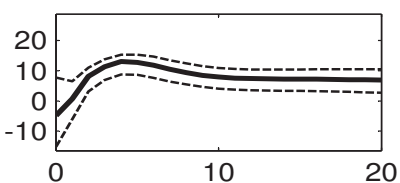

Gav Bonds France
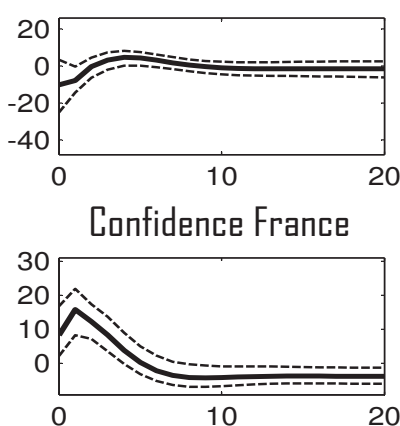

GDP Italy

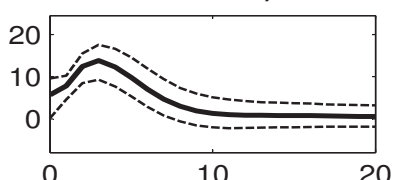

Consumption Italy

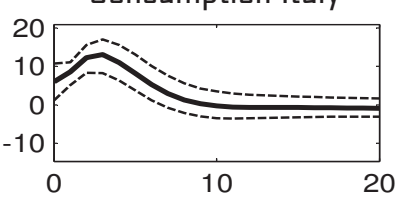

Investment Italy

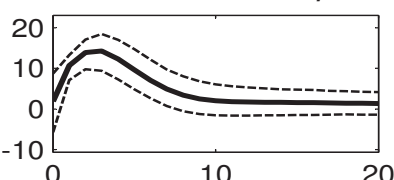

Gov. Expend. Italy

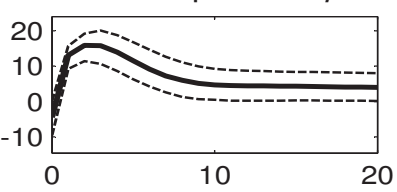

Real Wages Italy

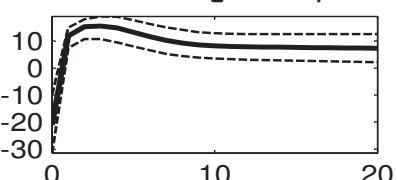

ULC Italy

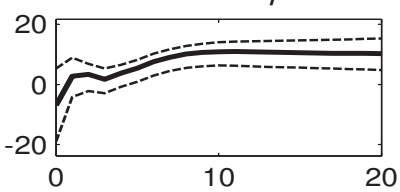

HCPI Italy

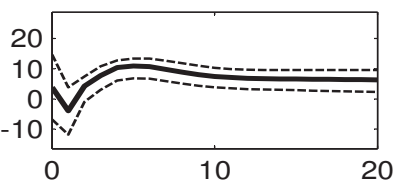

Gav Bonds Italy

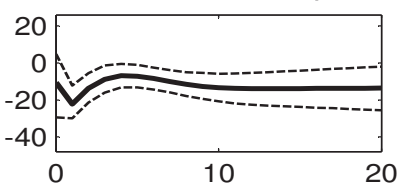

Confidence Italy

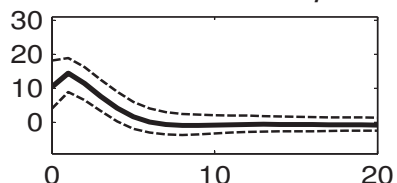

GDP Spain

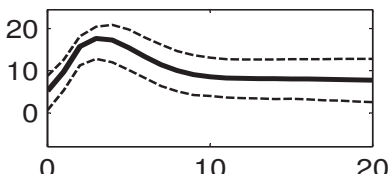

Consumption Spain
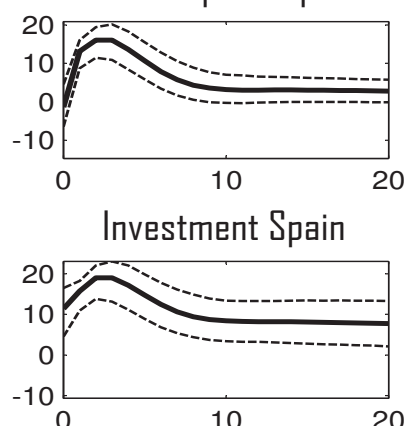

Gov. Expend. Spain

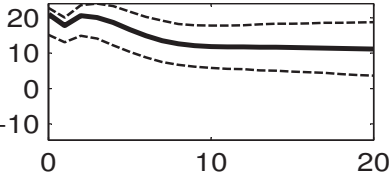

Real Wages Spain
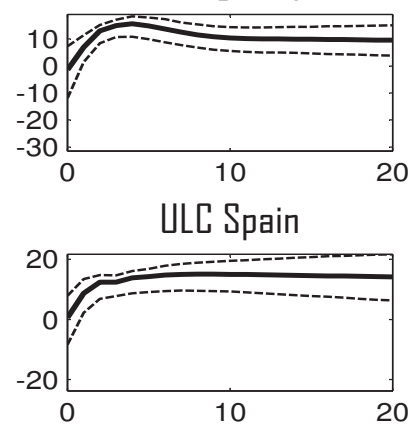

HСPI Spain
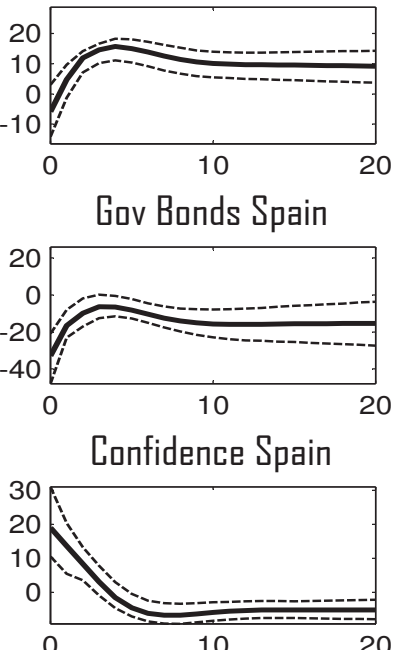

Figure 7: Non-coordinated Spending Shock: Spain. Impulse responses with 68\% CI 
GDP Germany

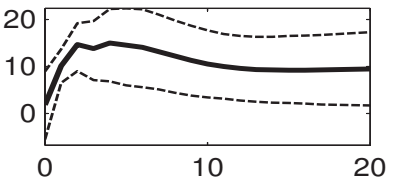

Consumption Germany
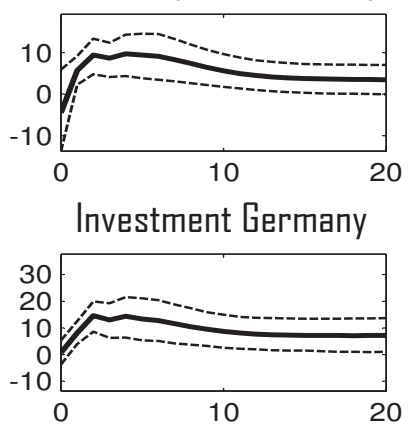

Gov Expend. Бermany

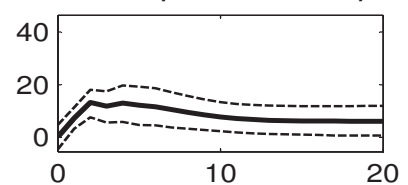

Real Wages Germany
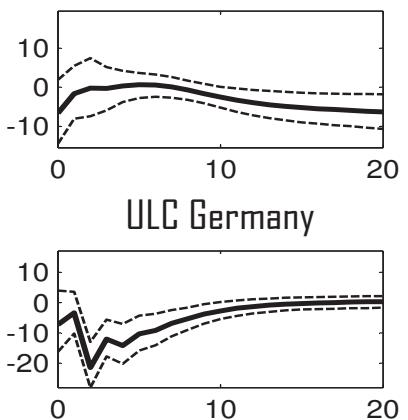

НСРІ Germany

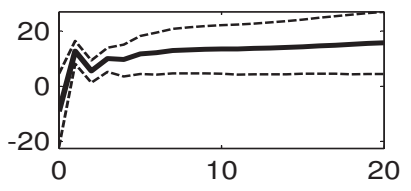

Gov Bunds Germany
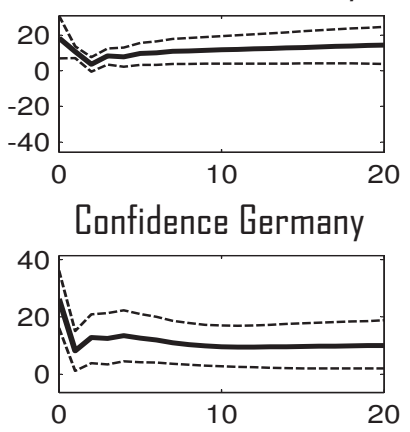

GDP France

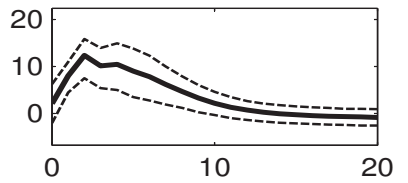

Consumption France

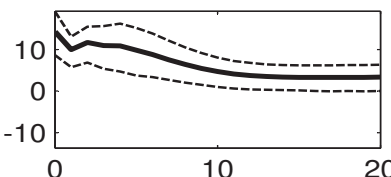

Investment France

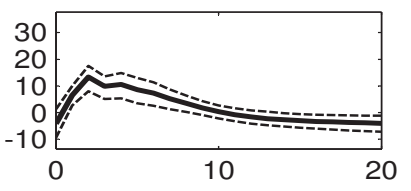

Gov. Expend. France

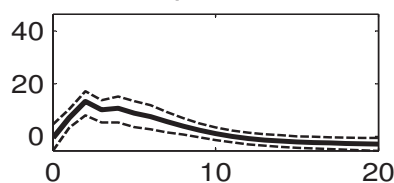

Real Wages France

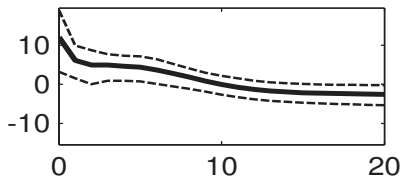

ULC France

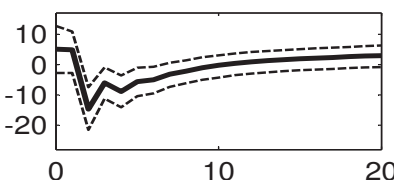

НСРI France

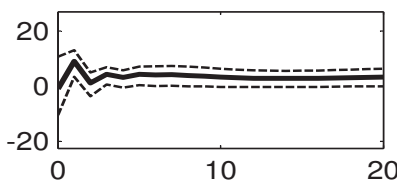

Gov Bonds France
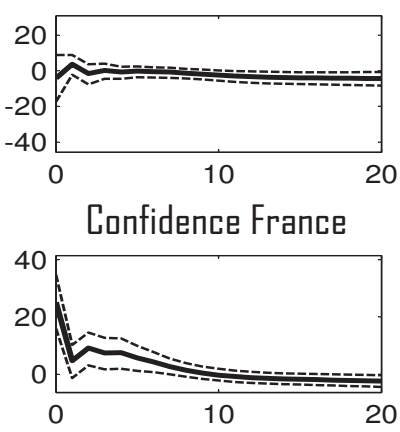

GDP Italy

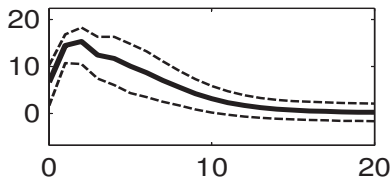

Consumption Italy

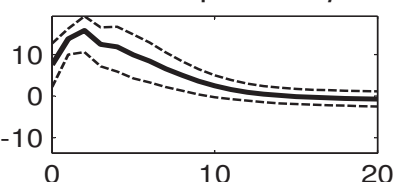

Investment Italy

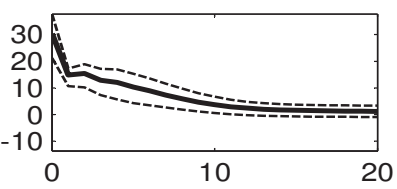

Gov. Expend. Italy

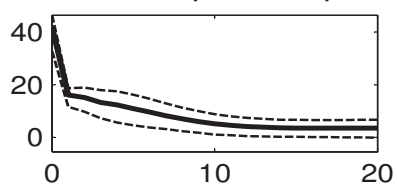

Real Wages Italy
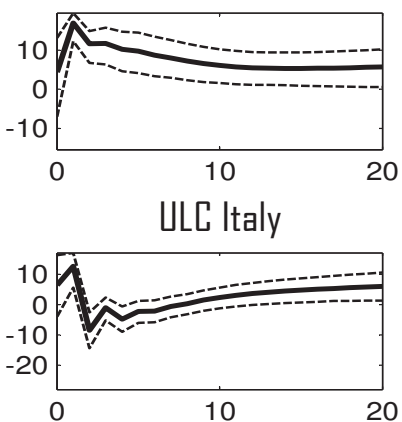

НСРI Italy

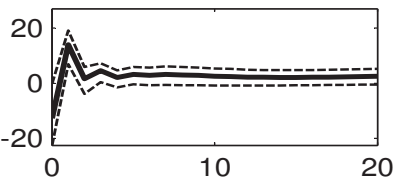

Gov Bonds Italy
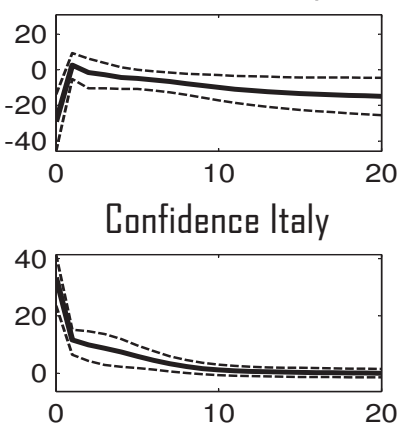

GDP Spain

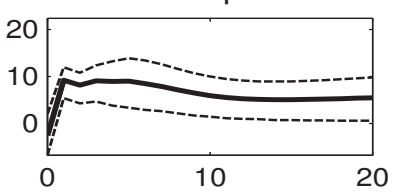

Consumption Spain

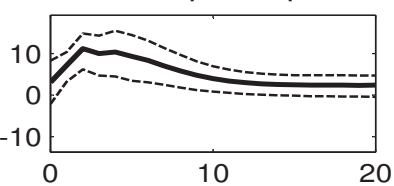

Investment Spain
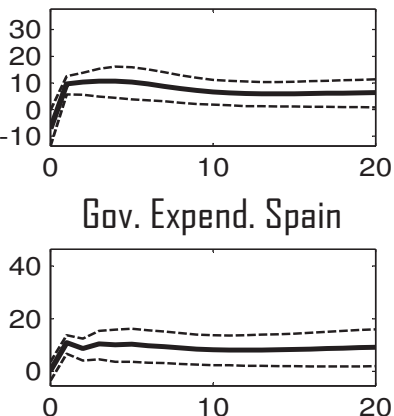

Real Wages Spain
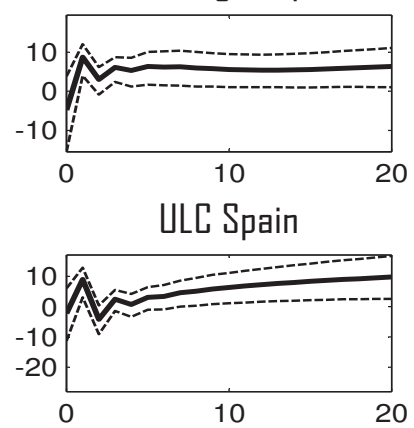

НСРІ Spain

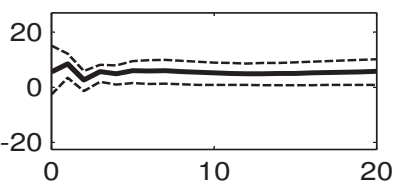

Gov Bonds Spain
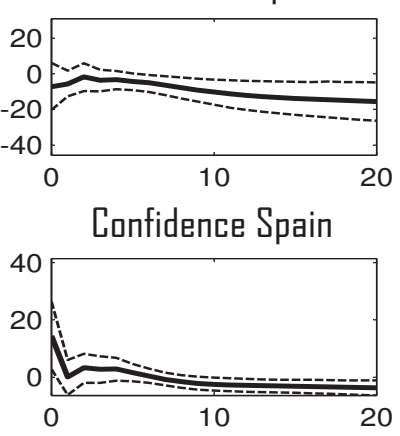

Figure 8: Non-coordinated Spending Shock: Italy. Impulse responses with $68 \%$ CI 
GDP Germany

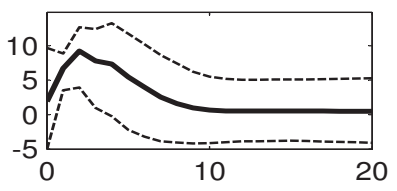

Consumption Germany

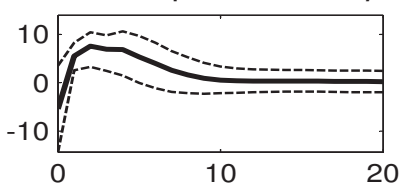

Investment Germany

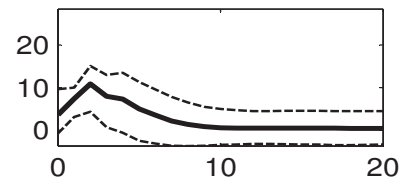

Gav Expend. Germany

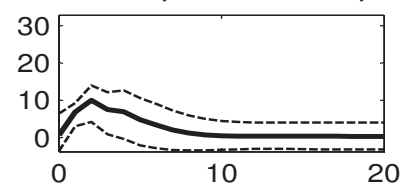

Real Wages Germany
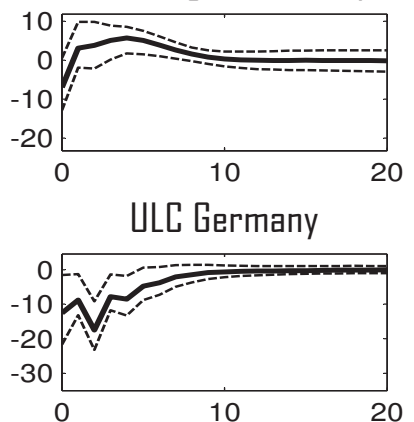

HСPI Germany

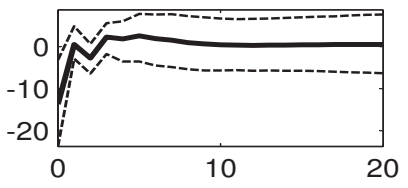

Gov Bands Germany
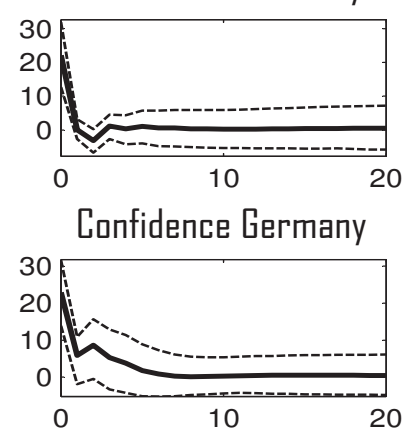

GDP France

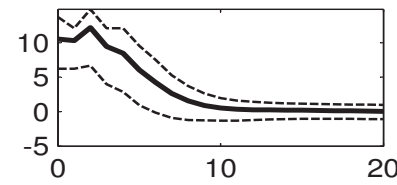

Consumption France

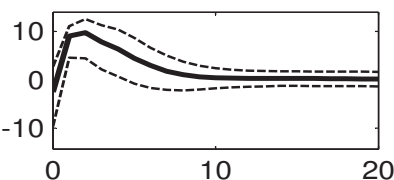

Investment France

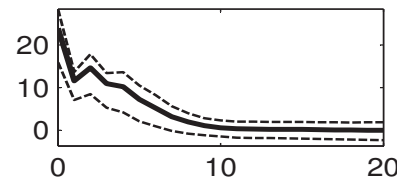

Gov. Expend. France

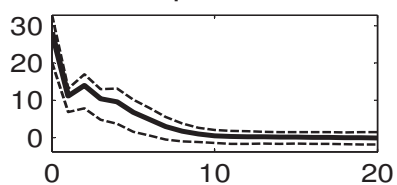

Real Wages France

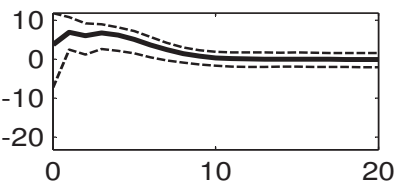

ULC France

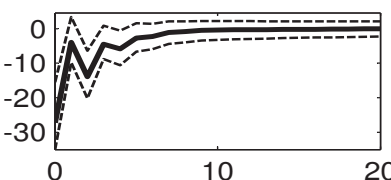

НСPI France

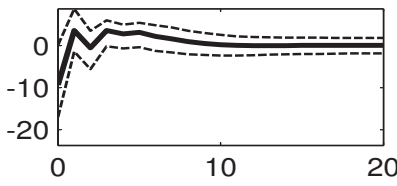

Gov Bonds France

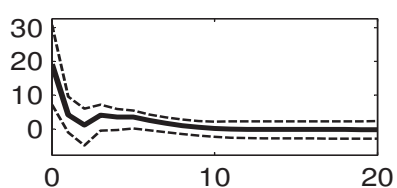

Canfidence France

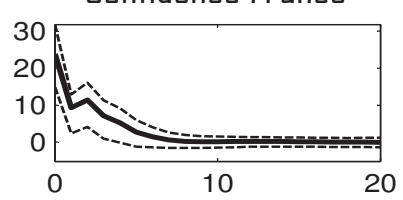

GDP Italy

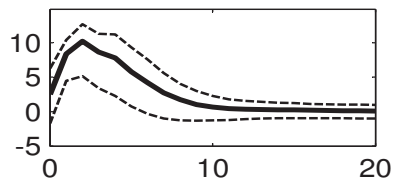

Consumption Italy

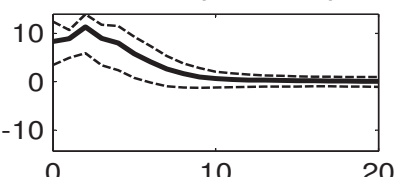

Investment Italy

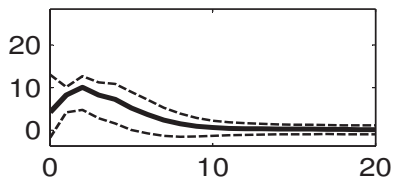

Gov. Expend. Italy

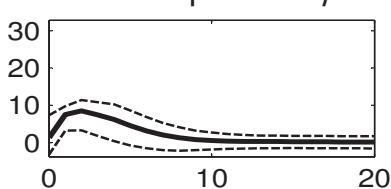

Real Wages Italy
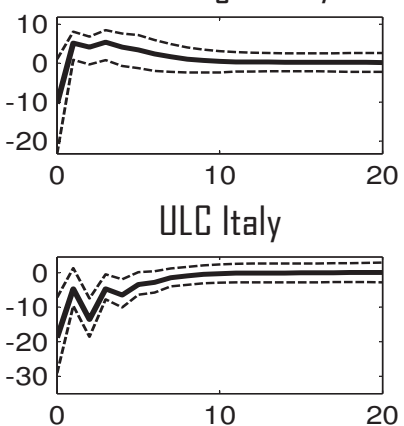

HCPI Italy

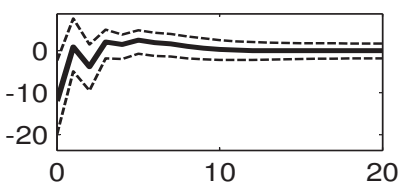

Gov Bands Italy
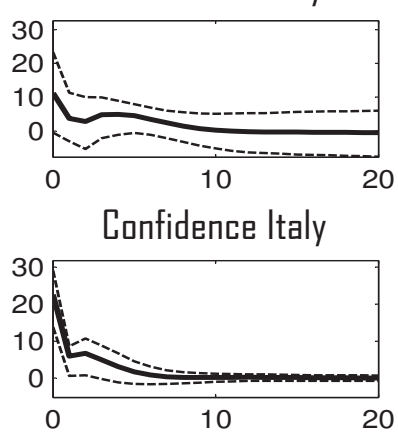

GDP Spain

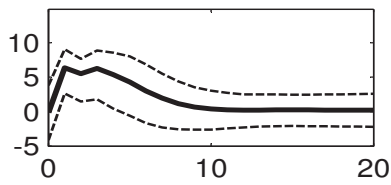

Consumption Spain

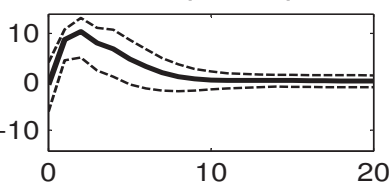

Investment Spain

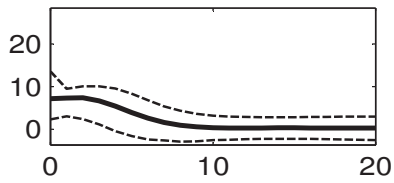

Gov. Expend. Spain

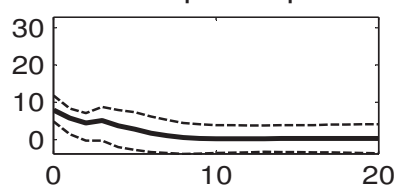

Real Wages Spain
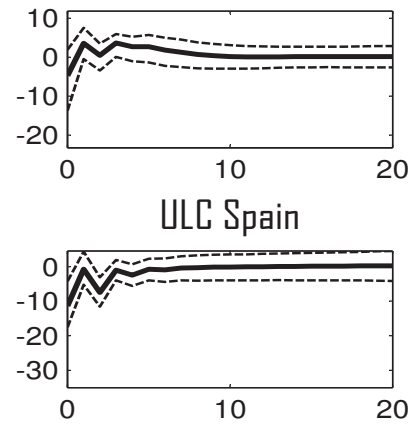

HСPI Spain

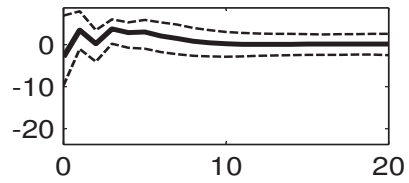

Gav Bands Spain
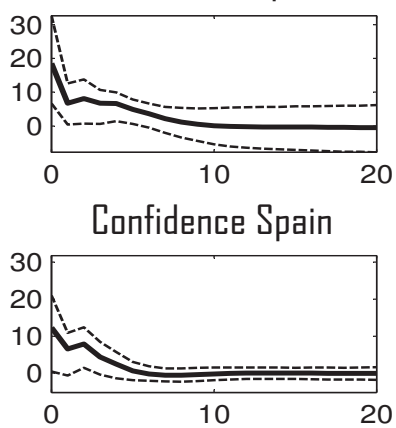

Figure 9: Non-coordinated Spending Shock: France. Impulse responses with 68\% CI 
GDP Germany

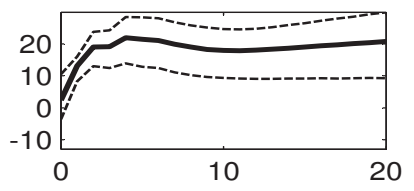

Consumption Germany

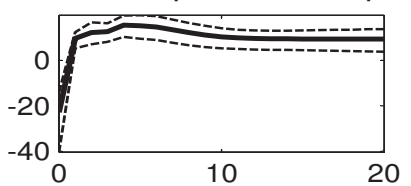

Investment Germany

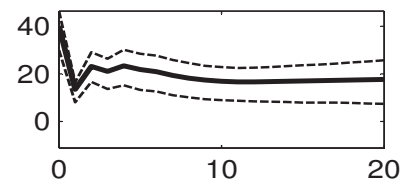

Gov Expend. Germany

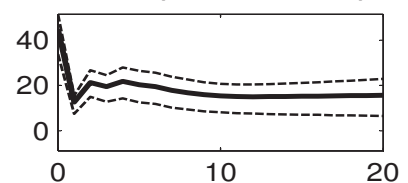

Real Wages Germany

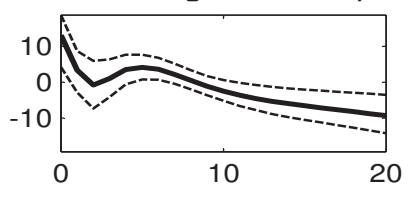

ULC Germany

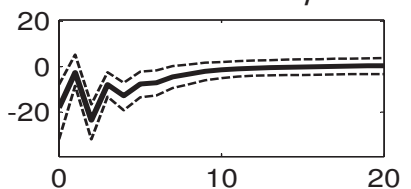

HCPI Germany

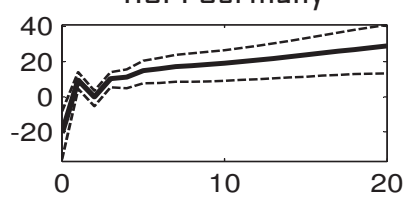

Gov Bonds Germany

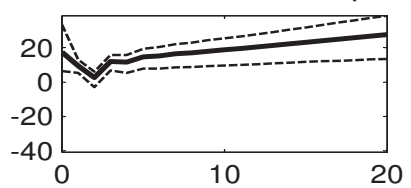

Confidence Germany

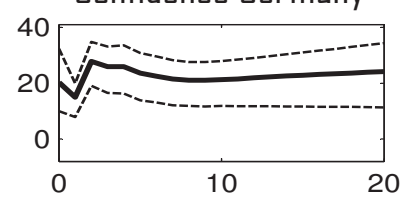

GDP France

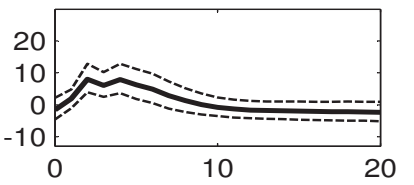

Consumption France

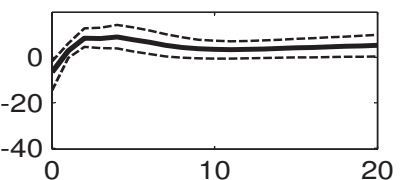

Investment France

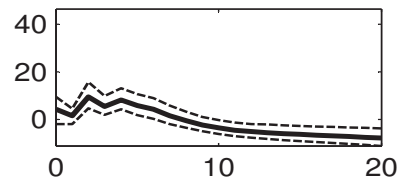

Gov. Expend. France

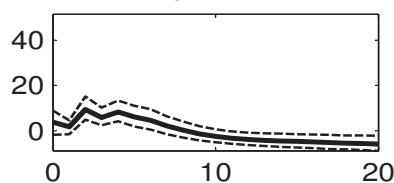

Real Wages France

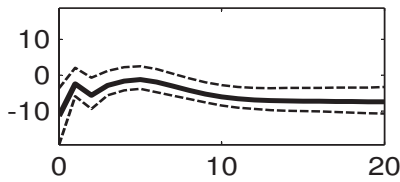

ULC France

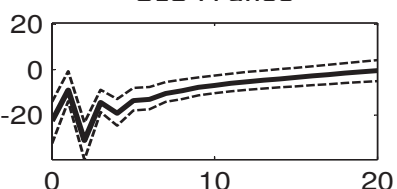

HCPI France

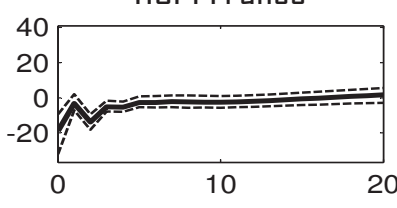

Gav Bonds France
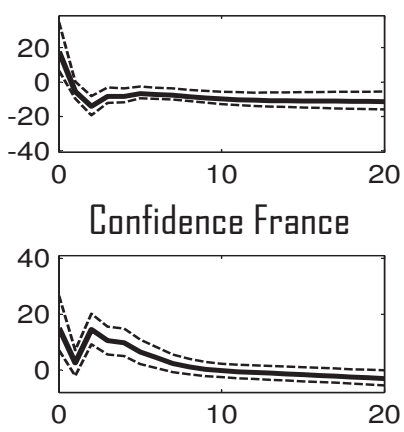

GDP Italy

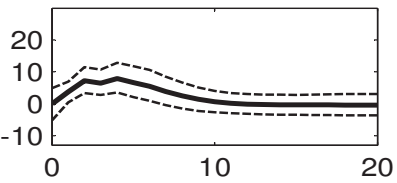

Consumption Italy

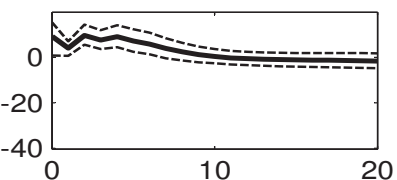

Investment Italy

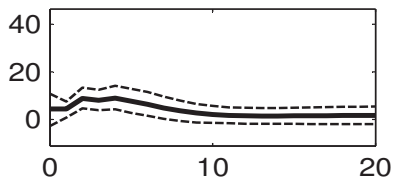

Gov. Expend. Italy

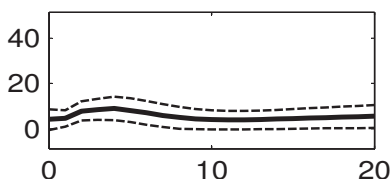

Real Wages Italy
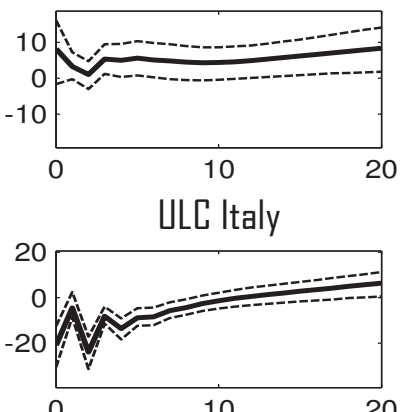

HCPI Italy

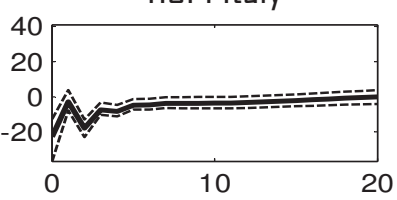

Gav Bonds Italy
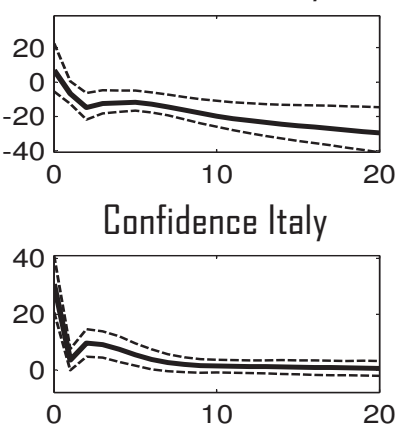

GDP Spain

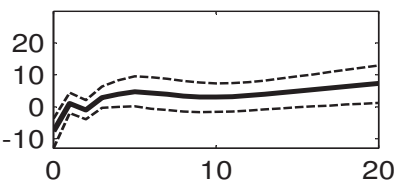

Consumption Spain
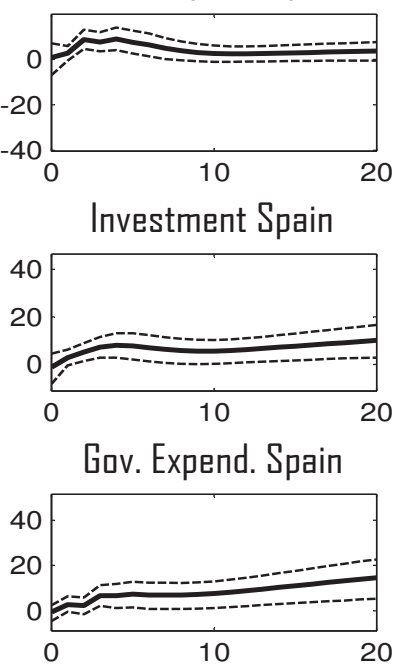

Real Wages Spain
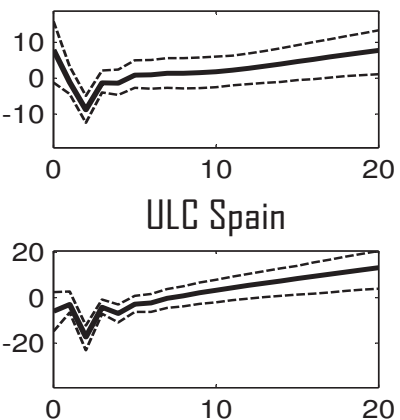

HСPI Spain

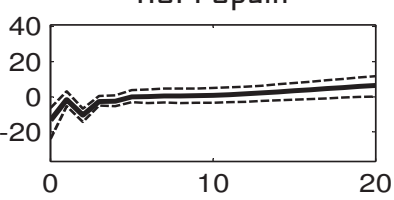

Gov Bands Spain
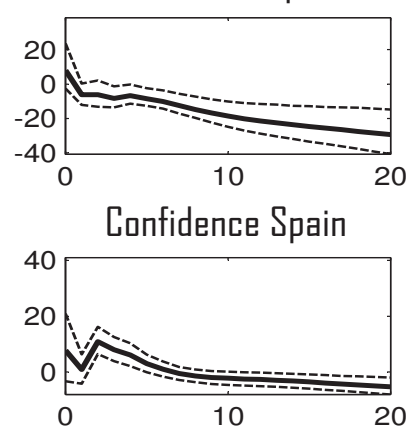

Figure 10: Non-coordinated Spending Shock: Germany. Impulse responses with 68\% CI 


\section{Appendix D: Coordinated fiscal shocks (Scenario 1)}

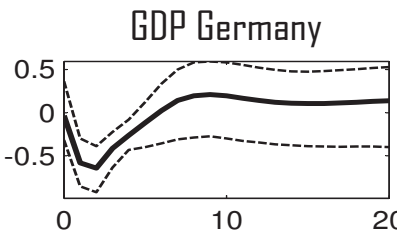

Consumption Germany

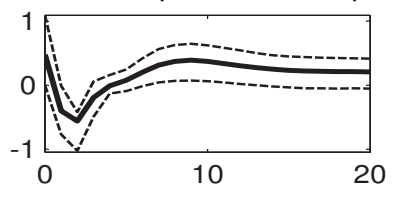

Investment Germany

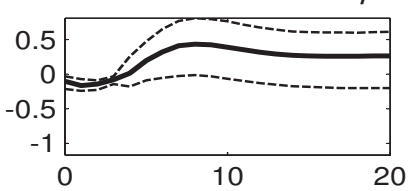

Gav Expend. Germany

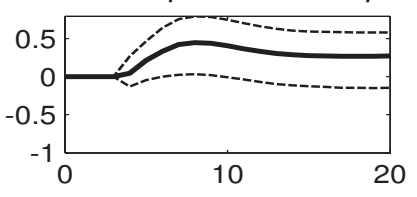

Real Wages Germany

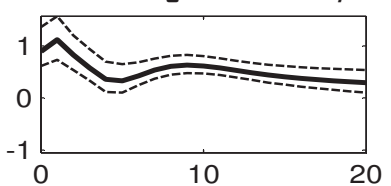

ULC Germany

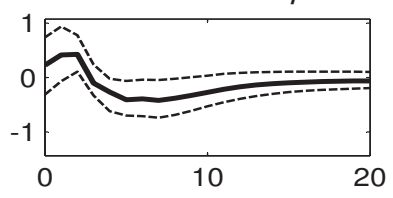

HCPI Germany
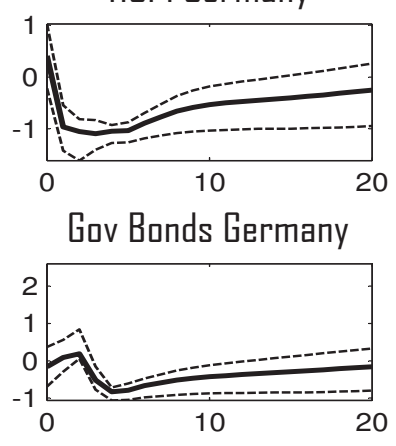

Confidence Germany

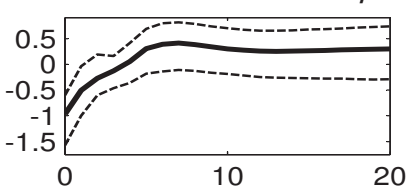

GDP France

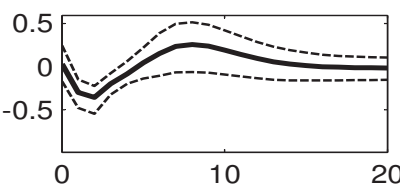

Consumption France
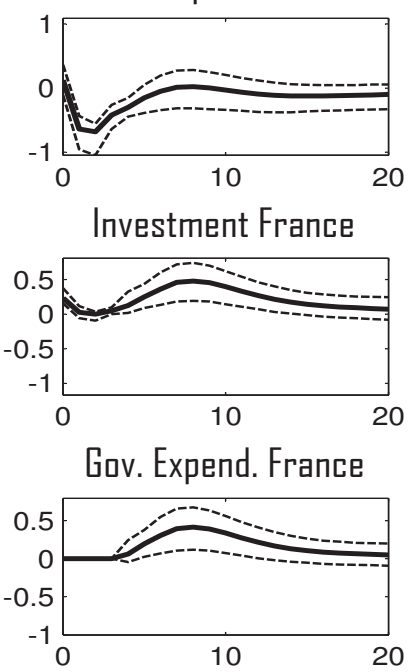

Real Wages France

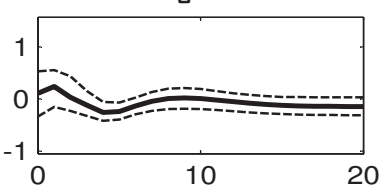

ULC France

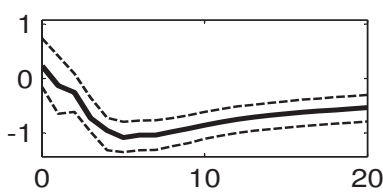

НСРI France

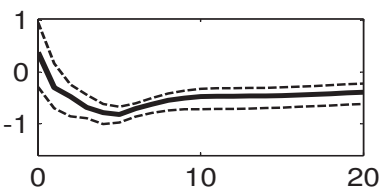

Gav Bands France
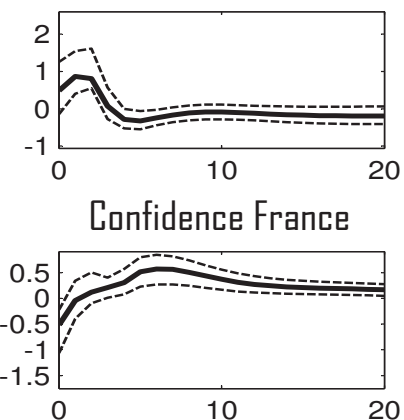
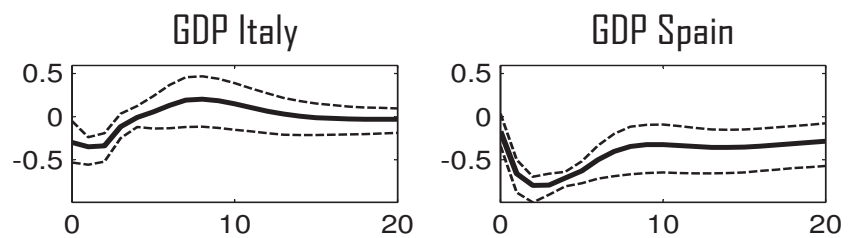

Consumption Italy

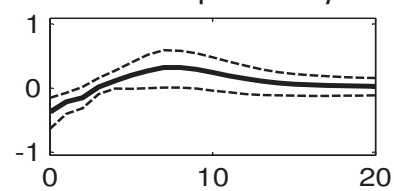

Investment Italy

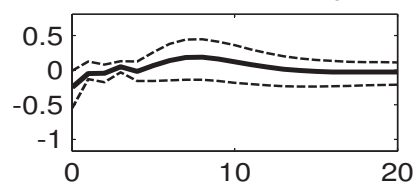

Gov. Expend. Italy

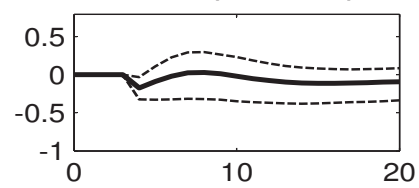

Real Wages Italy

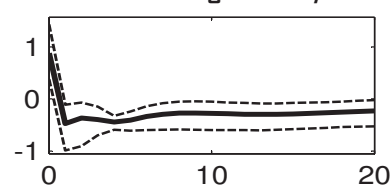

ULC Italy

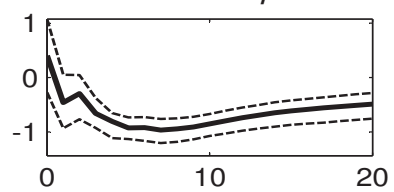

HCPI Italy

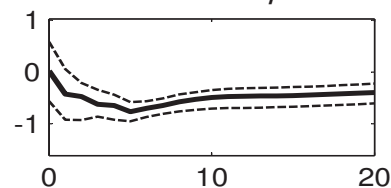

Gav Bonds Italy

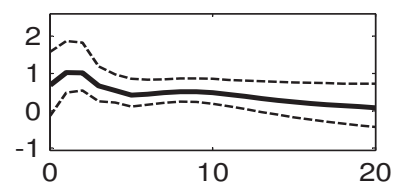

Canfidence Italy

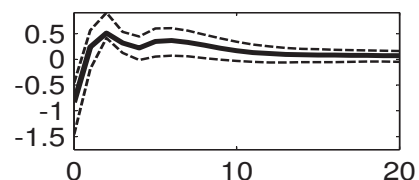

Consumption Spain
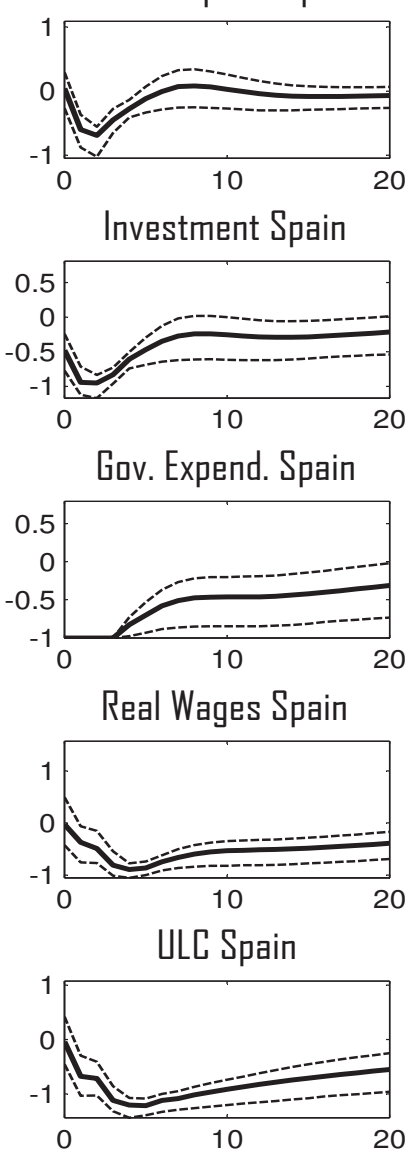

HСPI Spain

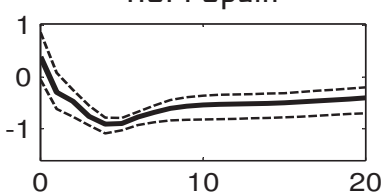

Gav Bands Spain
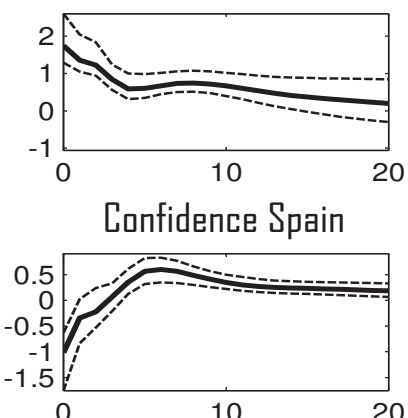

Figure 11: Coordinated Spending Shock: Spain. Impulse responses with 68\% CI 
GDP Germany

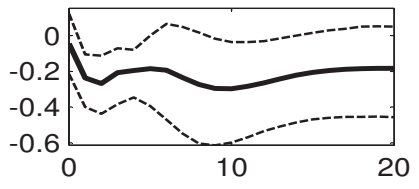

Consumption Germany

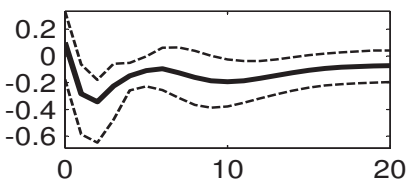

Investment Germany

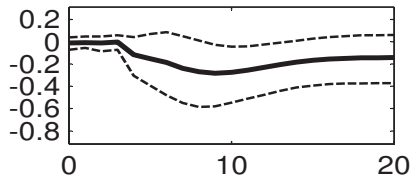

Gov Expend. Germany

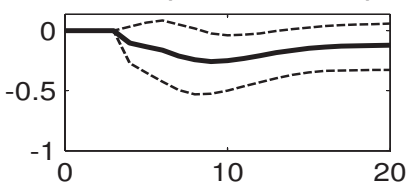

Real Wages Germany
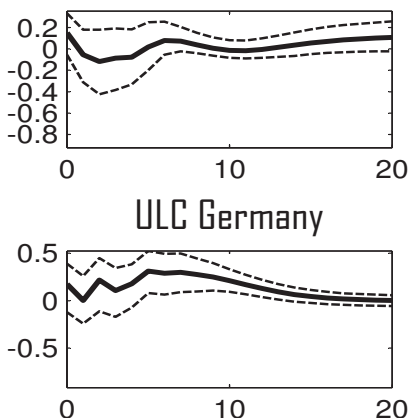

НСРI Germany

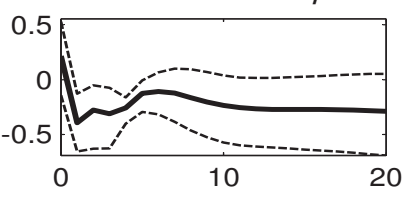

Gov Bands Germany

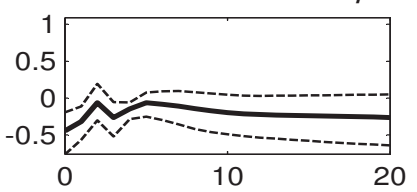

Confidence Germany

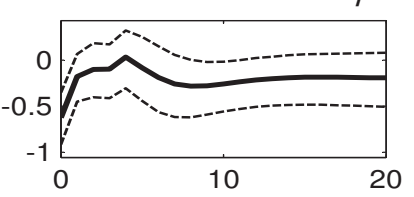

GDP France

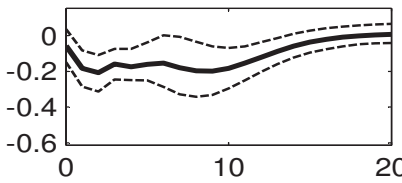

Cansumption France

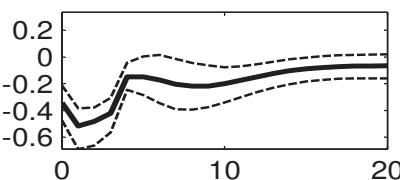

Investment France

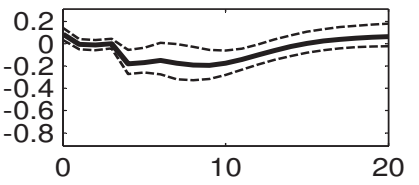

Gov. Expend. France

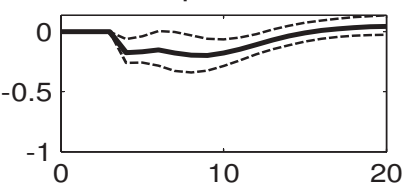

Real Wages France

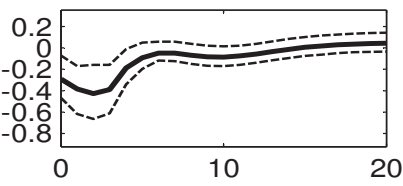

ULC France

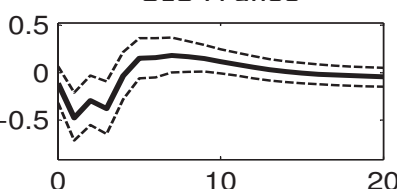

НСРI France

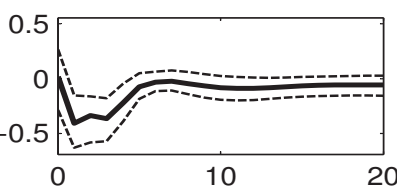

Gov Bonds France

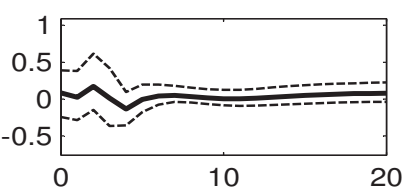

Confidence France

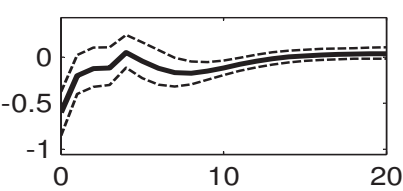

GDP Italy

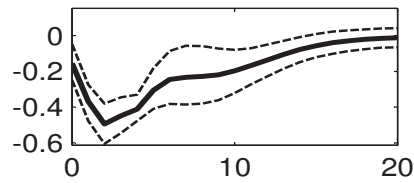

Consumption Italy

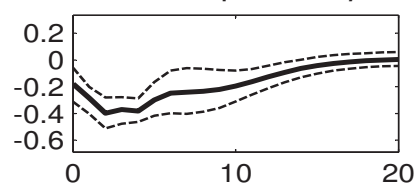

Investment Italy
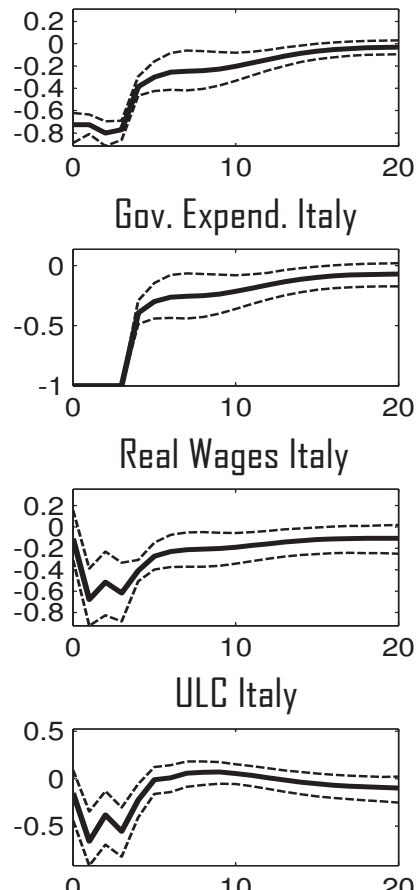

HCPI Italy

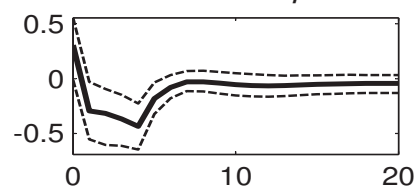

Gav Bonds Italy

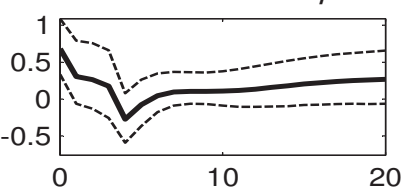

Confidence Italy

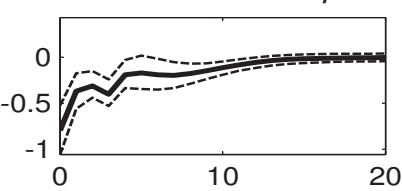

GDP Spain
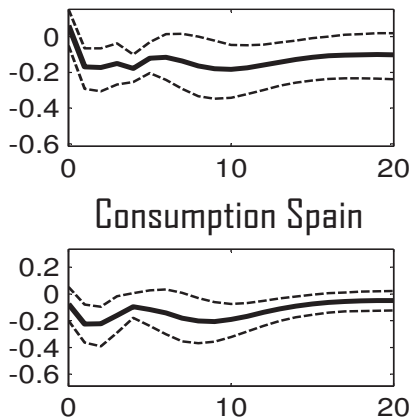

Investment Spain
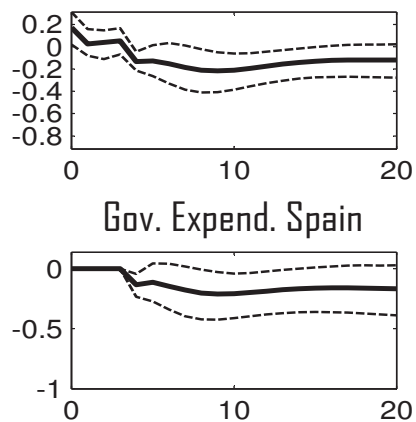

Real Wages Spain
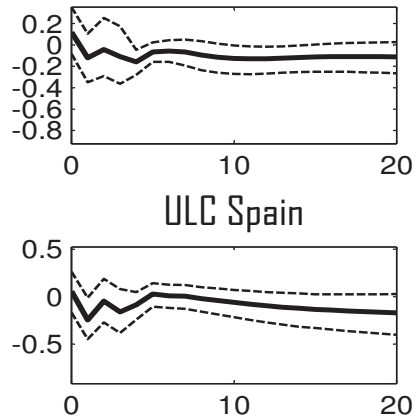

HСPI Spain
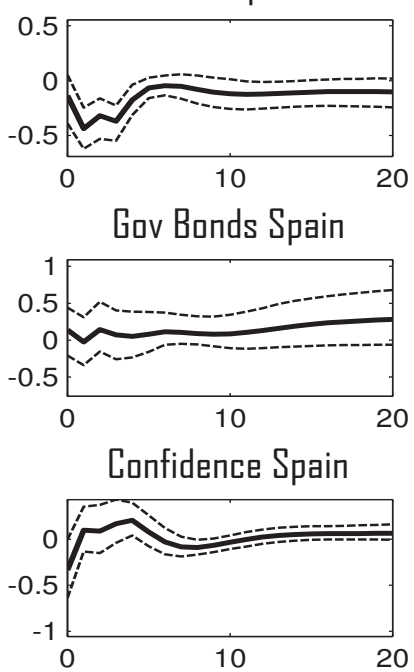

Figure 12: Coordinated Spending Shock: Italy. Impulse responses with $68 \%$ CI 
GDP Germany

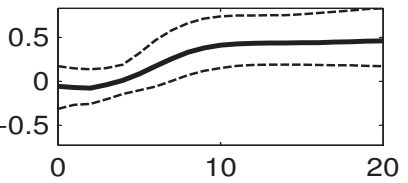

Consumption Germany

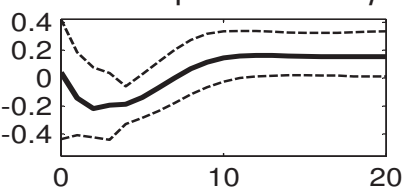

Investment Germany

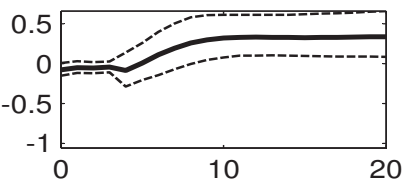

Gov Expend. Germany

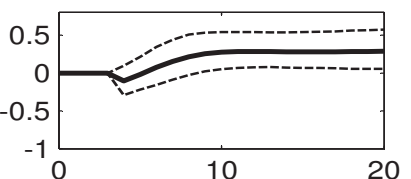

Real Wages Germany

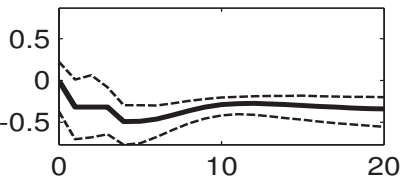

ULС Germany

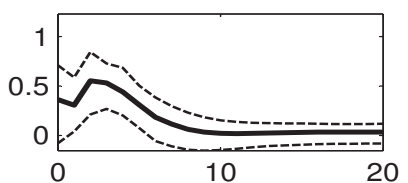

НСPI Germany

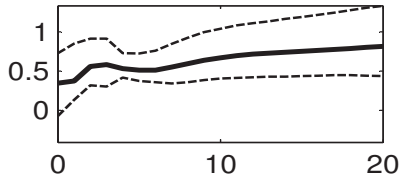

Gav Bands Germany

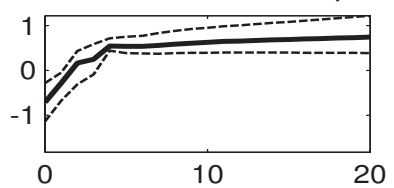

Confidence Germany

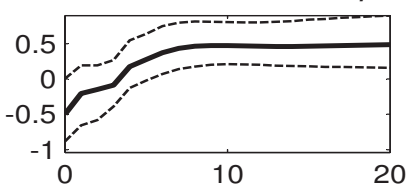

GDP France

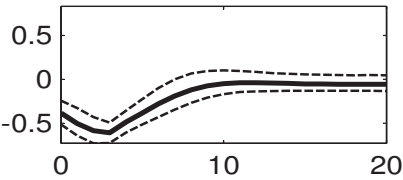

Consumption France

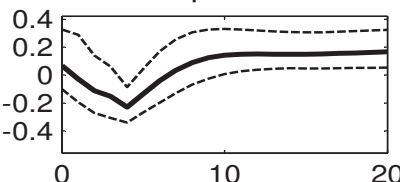

Investment France

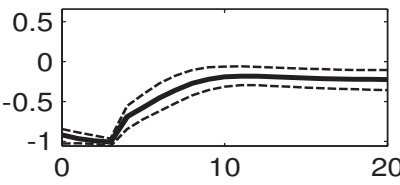

Gov. Expend. France

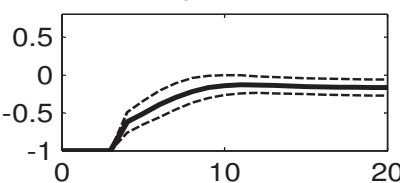

Real Wages France

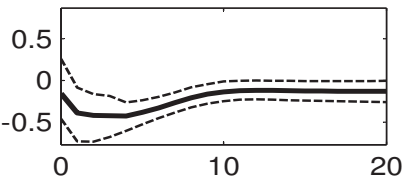

ULC France

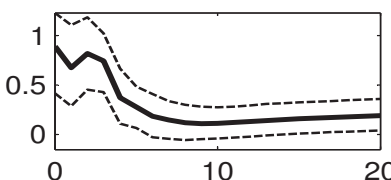

HCPI France

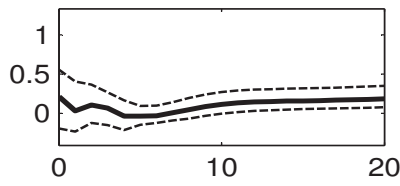

Gov Bands France

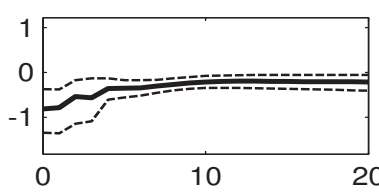

Canfidence France

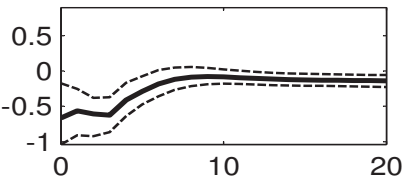

GDP Italy

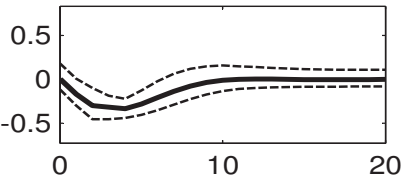

Consumption Italy

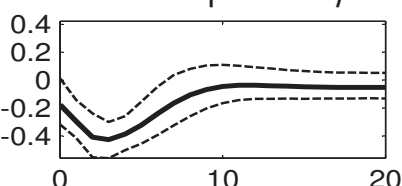

Investment Italy

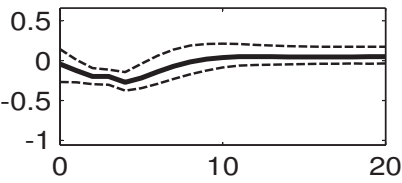

Gov. Expend. Italy

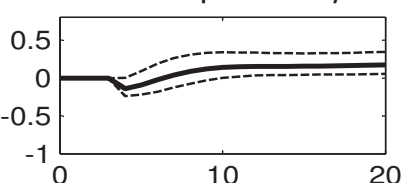

Real Wages Italy
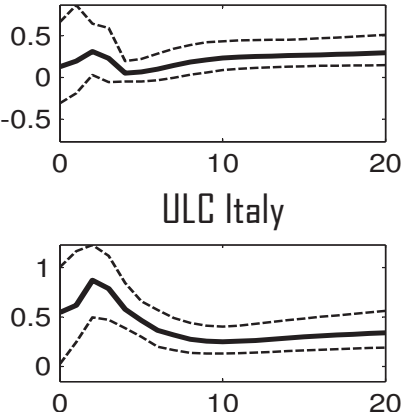

HCPI Italy

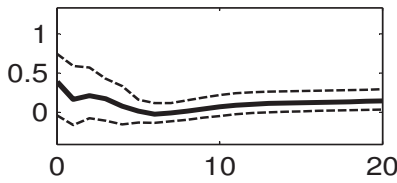

Gav Bands Italy

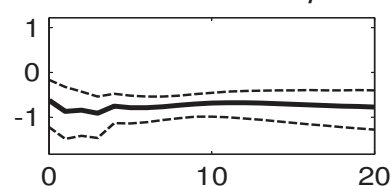

Confidence Italy

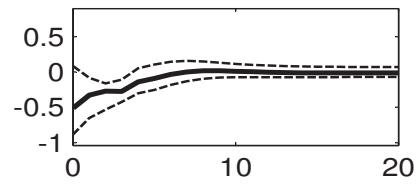

GDP Spain
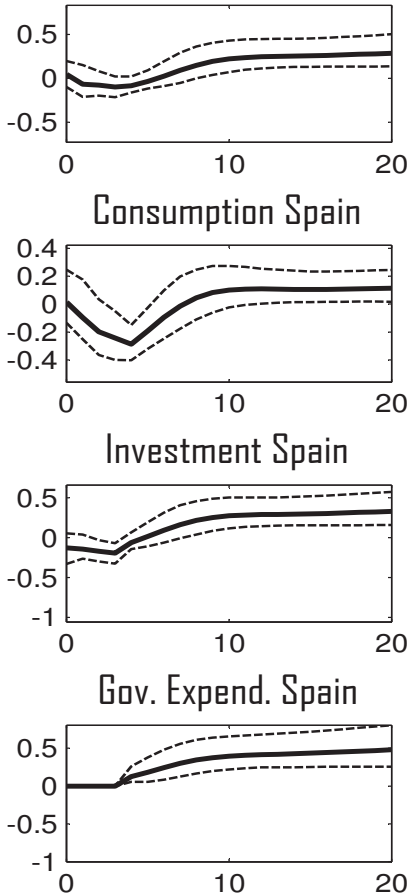

Real Wages Spain
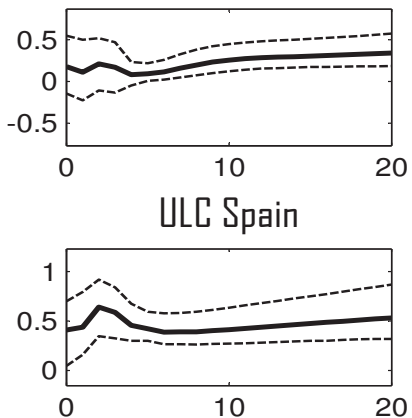

HСPI Spain

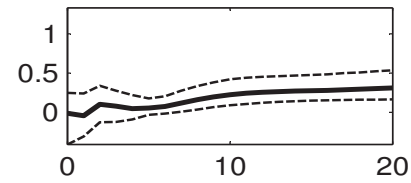

Gov Bonds Spain

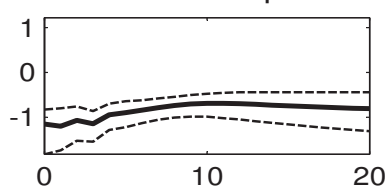

Confidence Spain

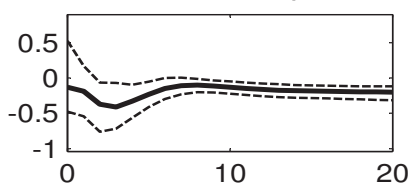

Figure 13: Coordinated Spending Shock: France. Impulse responses with 68\% CI 
GDP Germany

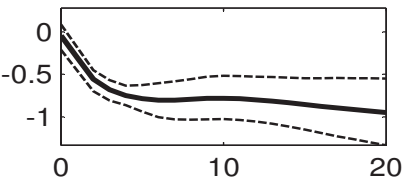

Consumption Germany

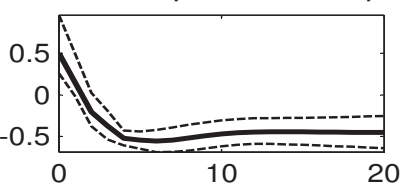

Investment Germany

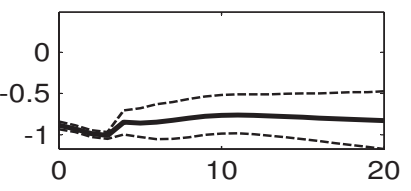

Gov Expend. Germany

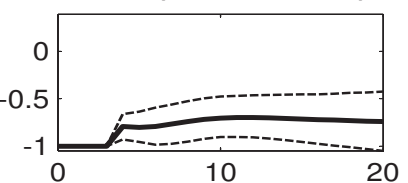

Real Wages Germany
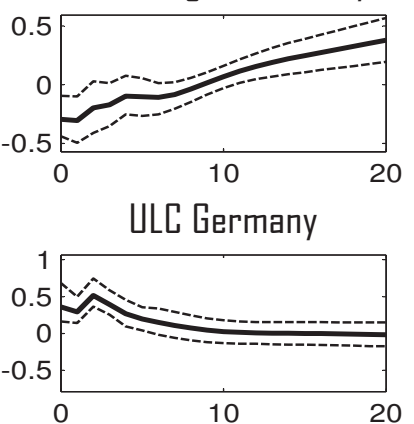

HCPI Germany

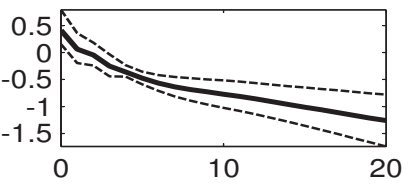

Gov Bonds Germany

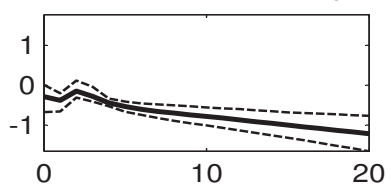

Canfidence Germany

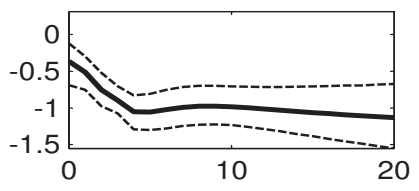

GDP France

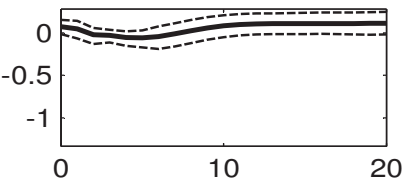

Cansumption France

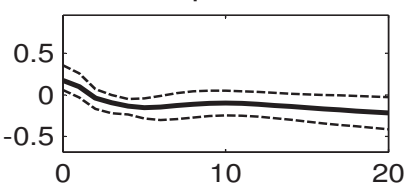

Investment France

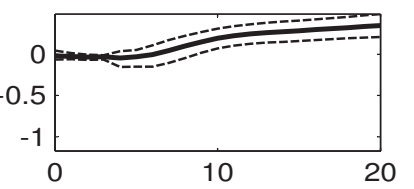

Gov. Expend. France

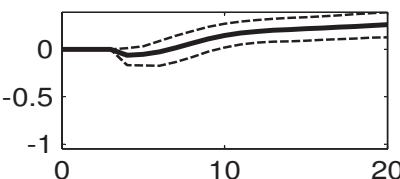

Real Wages France

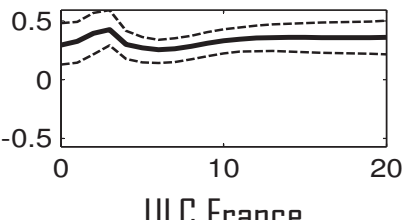

ULC France

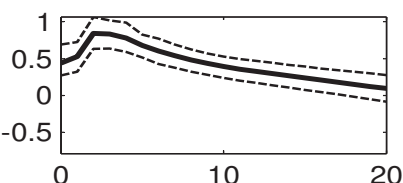

HCPI France

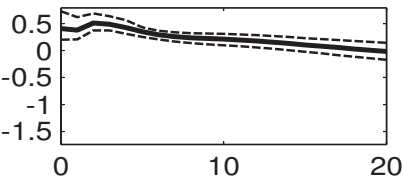

Gov Bonds France

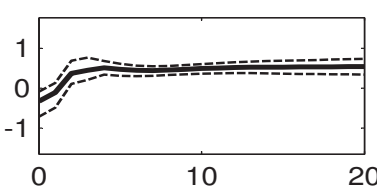

Confidence France

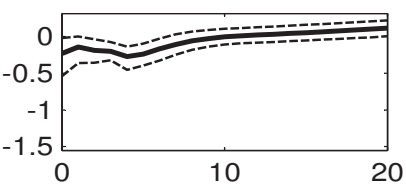

GDP Italy

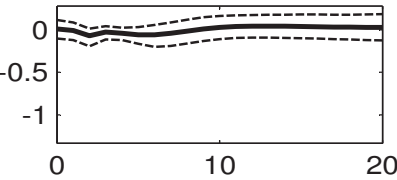

Consumption Italy

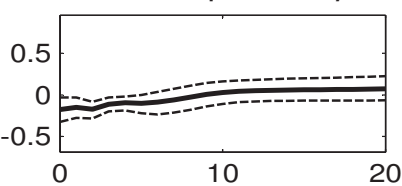

Investment Italy

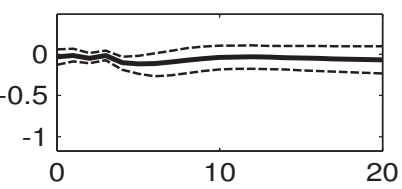

Gov. Expend. Italy

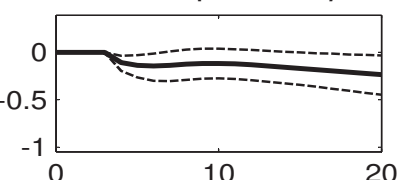

Real Wages Italy

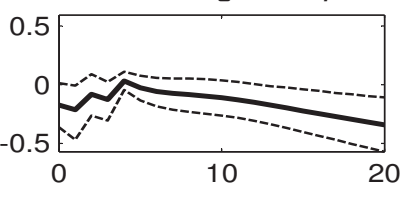

ULC Italy

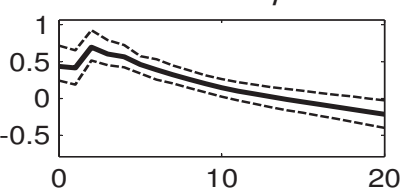

HCPI Italy

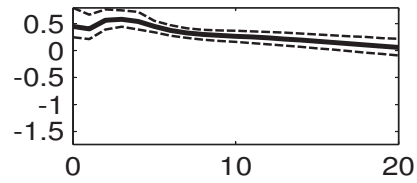

Gav Bonds Italy

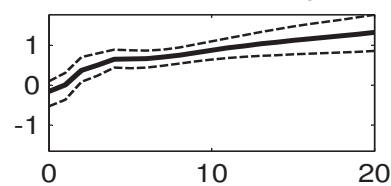

Confidence Italy

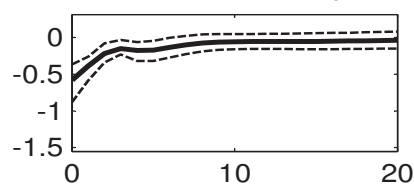

GDP Spain

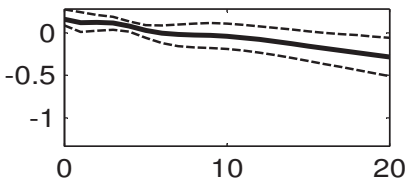

Consumption Spain

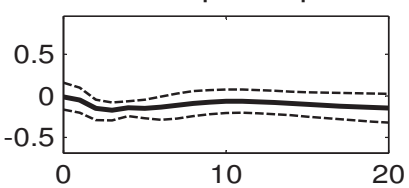

Investment Spain

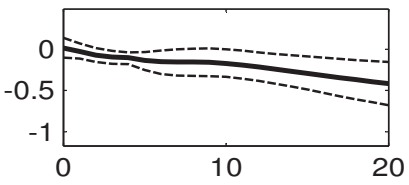

Gov. Expend. Spain

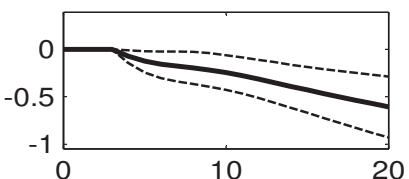

Real Wages Spain
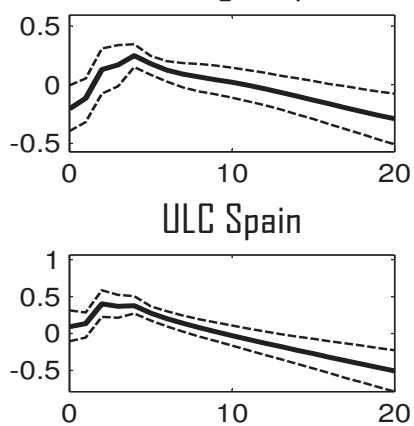

HCPI Spain

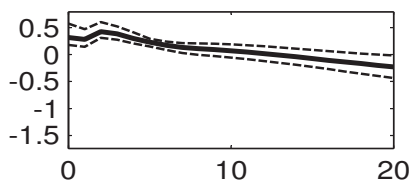

Gov Bonds Spain

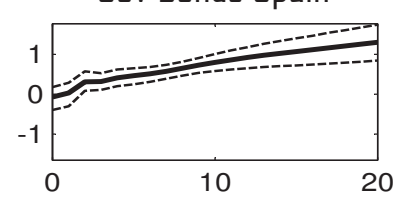

Confidence Spain

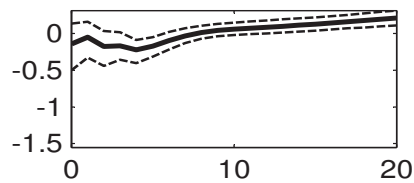

Figure 14: Coordinated Spending Shock: Germany. Impulse responses with 68\% CI 